\title{
NISTIR 4935
}

\section{Evaluation of Compact Fluorescent Lamp Performance at Different Ambient Temperatures}

Belinda L. Collins and Stephen J. Treado

Building and Fire Research Laboratory

Gaithersburg, Maryland 20899

Michael J. Ouellette

National Research Council Canada

Ottawa, Ontario K1A OR6 Canada

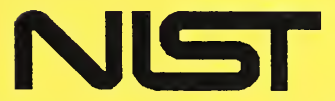

United States Department of Commerce Technology Administration

National Institute of Standards and Technology 



\section{Evaluation of Compact Fluorescent Lamp Performance At Different Ambient Temperatures}

Belinda L. Collins, Stephen J. Treado, and Michael J. Ouellette

December 1992

Building and Fire Research Laboratory

National Institute of Standards and Technology

Gaithersburg, MD 20899

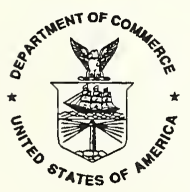

U.S. Department of Commerce

Barbara H. Franklin, Secretary

Technology Administration

Robert M. White, Under Secretary for Technology

National Institute of Standards and Technology

John W. Lyons, Director 


\section{Acknowledgements}

The authors would like to thank Phil Sanders for the initial instrumentation of the lamp testing apparatus at NIST. This project could not have been completed without his efforts. We would also like to thank Pete Rothfleish and Dave Ward who were responsible for the operation of the environmental chamber in which the lamps were tested, and Dr. Holly Rushmeier who digitized the flicker data for the flicker index calculations.

We would also like to acknowledge the support of the Canadian Electrical Association and Energy, Mines and Resources Canada to the National Research Council Canada and to the National Institute of Standards and Technology. Without their support, this project could not have been accomplished.

\section{Disclaimer}

Commercial products and trade names are provided in this report for informational purposes only, and do not constitute an endorsement or recommendation by the National Institute of Standards and Technology or the National Research Council of Canada. 


\section{Table of Contents}

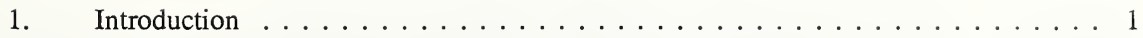

2. Procedure .......................... 1

2.1 Equipment . . . . . . . . . . . . . . . . . 1

2.2 Experimental Approach . . . . . . . . . . . . . . . 2

3. Experimental Results . . . . . . . . . . . . . . . . . . . . . . 4

3.1 Luminous Equilibrium Data . . . . . . . . . . . . . . . . 6

3.2 Lamp Performance Data at Equilibrium . . . . . . . . . . . . . . 17

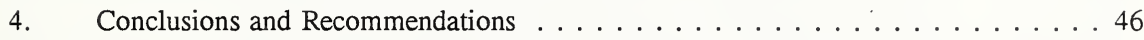

5. References . . . . . . . . . . . . . . . . . . . . . . . 47 
Figure 1. Time to Equilibrium and Relative Light Output for Lamp 1. . . . . . . . 7

Figure 2. Time to Equilibrium and Relative Light Output for Lamp 2. . . . . . . . . 8

Figure 3. Time to Equilibrium and Relative Light Output for Lamp 3. . . . . . . . . 9

Figure 4. Time to Equilibrium and Relative Light Output for Lamp 4. . . . . . . . . 11

Figure 5. Time to Equilibrium and Relative Light Output for Lamp 5. . . . . . . . . 12

Figure 6. Time to Equilibrium and Relative Light Output for Lamp 6. . . . . . . . . 13

Figure 7. Time to Equilibrium and Relative Light Output for Lamp 7. . . . . . . . 14

Figure 8. Time to Equilibrium and Relative Light Output for Lamp 8. . . . . . . . . 15

Figure 9. Time to Equilibrium and Relative Light Output for Lamp 9. . . . . . . . . 16

Figure 10. Time to Equilibrium and Relative Light Output for Lamp 10. . . . . . . . . 18

Figure 11. Time to Equilibrium and Relative Light Output for Lamp 11. . . . . . . . . 19

Figure 12. Time to Equilibrium and Relative Light Output for Lamp 13. . . . . . . . . 20

Figure 13. Ignition Time for all Lamps at Ambient Temperatures Above $-18^{\circ} \mathrm{C} . \quad \ldots .28$

Figure 14. Time to Luminous Equilibrium at Different Ambient Temperatures. . . . . . 29

Figure 15. Lamp Outer Wall Temperature at Different Ambient Temperatures. . . . . 30

Figure 16. Measured Luminance at Different Ambient Temperatures. . . . . . . . . . . 31

Figure 17. Measured Light Output at Different Ambient Temperatures. . . . . . . . . . 32

Figure 18. Photocell Output Relative to Luminance Meter Output as a Function of Ambient Temperature. . . . . . . . . . . . . . . . 34

Figure 19. Lamp and Ballast Power in Watts at Different Ambient Temperatures. . . . 35

Figure 20. Luminous Efficacy Relative to that at $25^{\circ} \mathrm{C}$ for Different Ambient Temperatures. . . . . . . . . . . . . . . . . 36

Figure 21. Luminous Efficacy Relative to that of Lamp 13 (Incandescent) at Different Ambient Temperatures. . . . . . . . . . . . . . . . . 38

Figure 22. Apparent Power (in Volt Amps) at Different Ambient Temperatures. . . . . . 39

Figure 23. Supply Current at Different Ambient Temperatures. . . . . . . . . . . . . . 40

Figure 24. Power Factor at Different Ambient Temperatures. . . . . . . . . . . . . . 41

Figure 25. Calculated Flicker Index at Different Ambient Temperatures. . . . . . . . . 42

Figure 26. Total Harmonic Distortion for Current at Different Ambient Temperatures. . . . . . . . . . . . . . . . . . . . 43

Figure 27. Total Harmonic Distortion for Voltage at Different Ambient Temperatures. . . . . . . . . . . . . . . . . . 44

Figure 28. Comparison of Initial and Repeated Performance at $25^{\circ} \mathrm{C} \ldots \ldots \ldots \ldots$

List of Tables

Table 1. Time to Ignition in Seconds for Each Lamp Set at Each Ambient Temperature . . . . . . . . . . . . . . . . . . 5

Table 2. Summary of Test Results for Each Lamp Set as a Function of Ambient Temperature ..................... 21 


\section{Introduction}

Compact fluorescent lamps are currently being used to replace incandescent lamps to aid in energy conservation in commercial and domestic lighting applications. In particular, they offer the benefits of much longer life and lower operating costs in a reasonably similar package (Bouwknegt, 1982). Some of the performance characteristics that the residential user is accustomed to may differ, however, for the newer lamp technology. Such characteristics include response to ambient thermal conditions, sensitivity to lamp position, flicker, harmonics, etc. Of particular concern is the response to ambient thermal conditions, since such lamps may be used in unconditioned spaces, such as garages, basements, barns, and similar spaces where they may be subjected to extremes in temperature, both hot and cold. While it is well known that fluorescent lamp performance is determined by the cold spot on the lamp and can be affected by the ambient temperature in the room (IESNA, 1984), the extent to which these findings, particularly for extreme in temperatures, apply to compact fluorescent lamp applications is not well understood.

In conjunction with the Institute for Research in Construction (IRC) at the National Research Council, Canada (NRCC), the Lighting Group at the National Institute of Standards and Technology (NIST) conducted an experimental evaluation of twelve sets of different types of compact fluorescent lamps at six different ambient temperature conditions. An additional set of incandescent lamps was also evaluated for comparison. A total of three lamps were tested for each of the thirteen lamp types, both compact fluorescent and incandescent.

\section{Procedure}

\subsection{Equipment}

Using a large environmental chamber, NIST performed a number of tests on the compact fluorescent samples at six different ambient temperatures. The compact fluorescent lamps were provided by NRCC/IRC and had been burned-in for approximately 100 hours prior to the NIST tests. Each set of tests involved measurements of a set of three identical compact fluorescent lamps mounted base-up on a metal frame suspended in the environmental chamber. Lamps were mounted on each of three arms radiating from a central area. The entire array was suspended from an overhead arm. Each lamp was approximately $60 \mathrm{~cm}$ from its neighbors and suspended about $1 \mathrm{~m}$ above a diffuse white plate and photocell used to monitor light output during the testing. The extent of tilt of the array was monitored by means of two bubble levels positioned at right angles in the central area of the lamp mounting arms. A second photocell mounted to the side of and about $0.5 \mathrm{~m}$ above the first photocell provided output to a Tektronix Oscilloscope to monitor flicker.

As noted above, a total of thirteen different sets of lamps were studied. Lamps 1-12 were compact fluorescents, while lamp 13 was a set of three $60 \mathrm{~W}$ incandescent lamps used as the reference lamp for comparison. All the compact fluorescent samples were designed to operate at 120 volts AC. Power ratings ranged from 13 to 28 watts. The compact fluorescent lamps were somewhat comparable in output to the incandescent lamps and could serve as likely replacements for them. The lamp sets are described as follows: 
Lamp $1 \mathrm{~T}_{4} 13 \mathrm{~W}$ twin tube with plug in magnetic ballast

Lamp $216 \mathrm{~W}$ globe with integral ballast and screw in base

Lamp $3 \quad \mathrm{~T}_{4} 20 \mathrm{~W}$ quad tube with integral ballast and screw in base

Lamp $4 \quad \mathrm{~T}_{4} 18 \mathrm{~W}$ globe with integral ballast and screw in base

Lamp $5 \quad \mathrm{~T}_{4} 13 \mathrm{~W}$ quad tube with integral ballast and screw in base

Lamp $6 \quad$ Lamp 5 with globe added

Lamp $7 \quad \mathrm{~T}_{4} 26 \mathrm{~W}$ quad tube with external ballast and mounting hardware

Lamp $8 \quad \mathrm{~T}_{5} 24 \mathrm{~W}$ twin tube with external ballast and mounting hardware

Lamp $9 \quad \mathrm{~T}_{5} 28 \mathrm{~W}$ quad tube with external ballast and mounting hardware

Lamp $10 \quad \mathrm{~T}_{4} 13 \mathrm{~W}$ twin tube with separate ballast adaptor and screw base

Lamp $11 \quad 13 \mathrm{~W}$ twin tube with integral ballast and screw in base

Lamp 12 Low voltage (12 V) $13 \mathrm{~W}$ twin tube with separate ballast and mounting hardware

Lamp $1360 \mathrm{~W}$ frosted incandescent aquarium lamp

Lamps 3 and 4 contained integral electronic ballasts, while all the other lamps had magnetic core ballasts, either separate or integral. Lamps 7 and 8 included high power factor correction circuits, while lamp 8 also contained a constant illumination circuit which was intended to provide constant illumination throughout a range of voltages. Since there were three samples for each lamp type, individual lamps in a set were designated as A, B, or C.

\subsection{Experimental Approach}

Lamp performance was evaluated for a total of six temperatures ranging from $45^{\circ} \mathrm{C}$ to $-18^{\circ} \mathrm{C}$, and including the burn-in temperature of $25^{\circ} \mathrm{C}$. The temperatures included $45,25,10,0,-9$, and $-18^{\circ} \mathrm{C}\left(113,77,50,32,16\right.$, and $0^{\circ}$ Fahrenheit). Temperature in the environmental chamber was maintained to within $\pm 1.5^{\circ} \mathrm{C}$. At each temperature condition, the following parameters were measured:

- $\quad$ Lamp ignition time or failure

- Time to luminous equilibrium and electrical stabilization

- Relative luminous flux density at a point $1 \mathrm{~m}$ below the central point

- Luminous flicker index for lamps with flicker rate below $240 \mathrm{~Hz}$

- $\quad$ Electrical power in watts and volt amps

- Minimum lamp wall or globe temperature as applicable

- Relative luminous efficacy

- Total harmonic distortion

- Power factor.

In addition, lamp performance was assessed for a simulated frost condition in which lamps were misted at $-4^{\circ} \mathrm{C}$ and time to ignition determined.

The luminous output of the lamps was measured in two ways. A silicon photocell was mounted $1 \mathrm{~m}$ below the center of the lamps and attached to Digitec Dataloger Model 2000 which recorded light output. The silicon cell was a photovoltaic cell with a $V \lambda$ filter, and a cosine diffuser amplifier. In addition, a Minolta luminance meter was used to measure luminance from the white plate located at the center of the three lamps also located $1 \mathrm{~m}$ below the mounting center. 
Although this meter was positioned about $2 \mathrm{~m}$ from the plate at about $30^{\circ}$ from normal for the measurements, it was located outside the chamber between measurements to minimize all thermal effects.

Luminance was measured once the lamps had been determined to be at luminous and electrical equilibrium. A third lamp output measure was that of Flicker Index, which was assessed once the lamps had reached equilibrium. Flicker was measured using a Tektronix oscilloscope which measured instantaneous light output from another photovoltaic silicon photocell mounted at the side of the test chamber in direct view of the lamps. This output was recorded manually and then digitized to calculate flicker index according to the following formula (IESNA, 1987,):

$$
\text { Flicker Index }=\quad \frac{\text { Area above average light output }}{\text { Area above average light output }+ \text { Area below average }}
$$

Finally, the temperature of each of the three lamps was measured by means of a thermocouple attached to the bottom tip of each lamp (or globe where applicable) and connected to the Digitec Dataloger as well. A fourth thermocouple monitored ambient temperature in the environmental chamber. The four temperature and luminous photocell outputs were recorded by the Digitec Dataloger every five minutes. All photocells and thermocouples were located in the environmental chamber throughout the measurement period. The photocell manufacturer reported minimal sensitivity to temperature extremes for the visual range at the temperatures tested.

A Basic Measurements Instrument (BMI) Model 3060 Power Profiler was used to record electrical information including voltage, current, power, total harmonic distortion, power factor and changes in electrical characteristics of the lighting systems over time. All electrical recording equipment was located in a room outside the environmental chamber to maintain temperature stability. (Luminance readings were taken rapidly once the lamps had reached equilibrium using a meter which was kept outside the chamber.) Power to the lamps was provided by means of a Sola MCR 500 power supply which maintained an input voltage at $122 \pm 1 \mathrm{~V}$ and THD $\pm 3 \%$. The low voltage system was powered by a $20 \mathrm{~V}$ DC power supply operating at $12 \pm 0.1 \mathrm{~V}$.

The three lamps were mounted on the test apparatus prior to beginning each test session and setting the temperature in the environmental chamber. After the environmental chamber (and lamps) had stabilized at the pre-determined test temperature, the lamps were ignited. Time to ignition was measured in seconds. Lamp wall and ambient temperature were measured and recorded every 5 minutes, while the electrical parameters were continuously monitored and recorded. In addition, a record of lamp system input electrical conditions was taken at the beginning and end of a test session for each lamp type. Lamp luminance and flicker was measured at the end of each test session. Throughout each test session, lamp light output was monitored using a silicon photocell. (This output is referred to subsequently as photocell output.) Lamps were considered to be at equilibrium when three light output (photocell) readings taken consecutively within 15 minutes did not differ by more than $\pm 1 \%$. Data are reported for all three lamps combined except where failure of one or more lamps occurred. 


\section{Experimental Results}

Lamp performance was measured for ambient temperatures in the following order: $25^{\circ}, 45^{\circ}$, $10^{\circ}, 0^{\circ},-9^{\circ},-18^{\circ},-4^{\circ} \mathrm{C}$ with mist, and $25^{\circ} \mathrm{C}$ again. The baseline condition, $25^{\circ} \mathrm{C}$, was repeated at the end to determine changes in lamp performance or the extent of lamp degradation as a function of thermal stress and operation. The results for the repeated condition are designated as $25 \mathrm{R}$. In addition, where one of the lamps failed during the course of the data collection, measures were repeated at $25{ }^{\circ} \mathrm{C}$ with only two lamps (noted as $25-2$ in the table). These results are summarized in Table 1.

The first result to be discussed is the time to lamp ignition or failure (when appropriate). Lamps were considered to have failed if they did not ignite within 5 minutes of being started. Since three lamps were assessed, there were three possibilities for failure. No lamps failed for temperatures greater than $0^{\circ} \mathrm{C}$. At $0^{\circ} \mathrm{C}$, however, there were two failures. Lamp 7B broke when tapped gently during the mounting procedure, and Lamp $8 \mathrm{~B}$ refused to start at this temperature. At $-9^{\circ} \mathrm{C}$ Lamp $5 \mathrm{C}$ refused to start, as did all three Lamp 8 's. At $-18^{\circ} \mathrm{C}$, Lamp $5 \mathrm{C}$ ignited only after tightening the wires in the socket. Lamp 12 refused to start at temperatures below $0^{\circ} \mathrm{C}$, with one lamp failing at the initial $25^{\circ} \mathrm{C}$ condition. This lamp failed because an uninsulated diode was shorted out after touching the "live" ballast housing. As a result, much less complete data were obtained for lamp 12. Lamp 5A (and consequently 6A) began to experience ignition problems at $10^{\circ} \mathrm{C}$. It required adjusting the socket and twisting the lamp to get it to ignite. It finally failed completely at $-18^{\circ} \mathrm{C}$. Most lamps evidenced problems at the coldest conditions $\left(-18^{\circ} \mathrm{C}\right.$ or $\left.0^{\circ} \mathrm{F}\right)$ with only lamps $3,4,9$, and of course 13 starting rapidly. 
Table 1. Time to Ignition in Seconds for Each Lamp Set at Each Ambient Temperature.

\begin{tabular}{|c|c|c|c|c|c|c|c|c|}
\hline $\begin{array}{l}\text { Lamp } \\
\text { Number }\end{array}$ & $25^{\circ} \mathrm{C}$ & $45^{\circ} \mathrm{C}$ & $10^{\circ} \mathrm{C}$ & $0^{\circ} \mathrm{C}$ & $\begin{array}{l}-4^{\circ} \mathrm{C} \\
\text { Mist }\end{array}$ & $-9^{\circ} \mathrm{C}$ & $-18^{\circ} \mathrm{C}$ & $25 \mathrm{R}$ \\
\hline $\begin{array}{l}\# 1 \\
13 \mathrm{~W} \text { TT }\end{array}$ & 3 & 2.5 & 3.5 & 5 & 2 & 3 & $\begin{array}{l}25 \mathrm{C} \\
13 \mathrm{~A} \& \mathrm{~B}\end{array}$ & 3 \\
\hline $\begin{array}{l}\# 2-16 \mathrm{~W} \\
\text { Globe }\end{array}$ & 0.5 & 2 & 3 & 5 & 3 & 6 & 11 & 3 \\
\hline $\begin{array}{l}\text { \# } 3-20 \mathrm{~W} \\
\text { QT }\end{array}$ & 1 & 1.5 & 1.5 & 2 & 1 & 2 & 3 & 2 \\
\hline $\begin{array}{l}\text { \# } 4-18 \mathrm{~W} \\
\text { Globe }\end{array}$ & 3 & 1.5 & 3 & 5 & Failed & 5 & 5 & 3.5 \\
\hline $\begin{array}{l}\text { \# } 5-13 \mathrm{~W} \\
\text { QT }\end{array}$ & 5 & 5 & 4.5 & $\begin{array}{c}6.5 \\
\text { A } \\
\text { Slow }\end{array}$ & Failed & $\begin{array}{c}25 \\
\text { A } \\
\text { Failed }\end{array}$ & $\begin{array}{c}205 \\
\text { A } \\
\text { Failed }\end{array}$ & 7 \\
\hline $\begin{array}{l}\text { \# } 6-13 \mathrm{w} \\
\text { Globe }\end{array}$ & 5. & 5 & 5 & 5 & 5 & 25 & $\begin{array}{c}451 \\
\text { A } \\
\text { Failed }\end{array}$ & 6 \\
\hline $\begin{array}{l}\text { \# } 7-26 \mathrm{~W} \\
\text { QT }\end{array}$ & 2.5 & 3 & 4 & $4^{1}$ & 3 & 5 & 411 & 3 \\
\hline $\begin{array}{l}\text { \# } 8-24 \mathrm{~W} \\
\text { TT }\end{array}$ & 2.5 & 0.5 & 0.5 & 1.5 & Failed & Glowed & Failed & 0.5 \\
\hline $\begin{array}{l}\text { \# } 9-28 \mathrm{~W} \\
\text { QT }\end{array}$ & 2.5 & 1.5 & 4.5 & 3.5 & 2 & 4 & 4 & 3.5 \\
\hline $\begin{array}{l}\# 10-13 \mathrm{~W} \\
\mathrm{QT}\end{array}$ & 4 & 4 & 4.5 & 3.5 & 5 & 20 & 130 & 4 \\
\hline $\begin{array}{l}\text { \# } 11 \\
13 \mathrm{~W} \text { TT }\end{array}$ & 5.5 & 4 & 3.5 & 5 & 5 & 40 & $\begin{array}{l}360 \\
170 \mathrm{C}\end{array}$ & 5 \\
\hline $\begin{array}{l}\# 12-13 \mathrm{~W} \\
\text { TT LoV }\end{array}$ & & 5 & 5 & 5 & & Failed & Failed & 5 \\
\hline $\begin{array}{l}\text { \# } 13-60 \mathrm{~W} \\
\text { Incand }\end{array}$ & 0.5 & 0.5 & 0.5 & 0.5 & & 0.5 & 0.5 & 0.5 \\
\hline
\end{tabular}

${ }^{1} 7 \mathrm{C}$ just broke before $0^{\circ} \mathrm{C}$ condition due to its increased fragility in the cold 


\subsection{Luminous Equilibrium Data}

Figures 1 through 12 present data on the time to luminous equilibrium, as well as for total light output over time for all lamps except lamp 12. Luminous equilibrium was defined as three consecutive readings that did not deviate by more than $1 \%$ from the immediately preceding measurement. Data for determining luminous equilibrium were typically collected for 60-90 minutes. In the figures, light output (measured by the photocell) is plotted as a function of time measured in 5 minute increments following ignition. The upper plot presents light output as a function of time after ignition, while the lower plot presents the relative light output, also as a function of time. Relative light output was determined by averaging the last three photocell readings, and then dividing each prior reading by this mean. In this way, deviation from equilibrium can be seen more clearly. Although it appears paradoxical, values greater than 1 in the lower plots indicate that initial light output was greater than that at the final equilibrium condition. Both plots clearly demonstrate the effects of changes in ambient temperature.

In Figure 1 which presents data for lamp 1, the upper portion of the page presents data on the absolute time to equilibrium as well as changes in light output over time, while the lower plot presents data on the light output relative to the final value over this time period. In these and the next 13 plots, the open diamonds represent the baseline data for $25^{\circ} \mathrm{C}$. As can be seen, light output was almost identical for 25 and $45^{\circ} \mathrm{C}$, with time to equilibrium achieved rapidly and maintained for 1 to 1.5 hours. At $10^{\circ} \mathrm{C}$ light output reached the same levels but then declined to a new, much lower equilibrium level after 60-70 minutes. At even cooler temperatures, represented by line symbols, light output peaked and then declined markedly with equilibrium occurring after about 60-70 minutes. The lower plot demonstrates that relative light output declined steadily over time at the cooler temperatures to a value of less than half that at $25^{\circ} \mathrm{C}$.

Figure 2 presents the same type of data for lamp 2. Unlike lamp 1, the data for lamp 2 showed much less variation over time as a function of temperature, although the data showed a peculiar initial decline in output for the two higher temperatures followed by a return to approximately the same light output obtained for the other temperatures. Total light output was much higher than for Lamp 1 and was much less affected by changes in room temperature; perhaps because of the presence of a globe which insulated it.

Figure 3 indicates that the time to luminous equilibrium for lamp 3 and the relative light output shown in the lower plot was about the same regardless of temperature. The upper plot shows, however, that overall light output was highly temperature dependent, dropping markedly for temperatures below $0^{\circ} \mathrm{C}$. Overall light output also tended to vary for low temperatures with the lamps not really reaching a stable equilibrium at either -9 or $-18^{\circ} \mathrm{C}$ during the first 90 minutes of operation. 
Figure 1. Time to Equilibrium and Relative Light Output for Lamp 1.

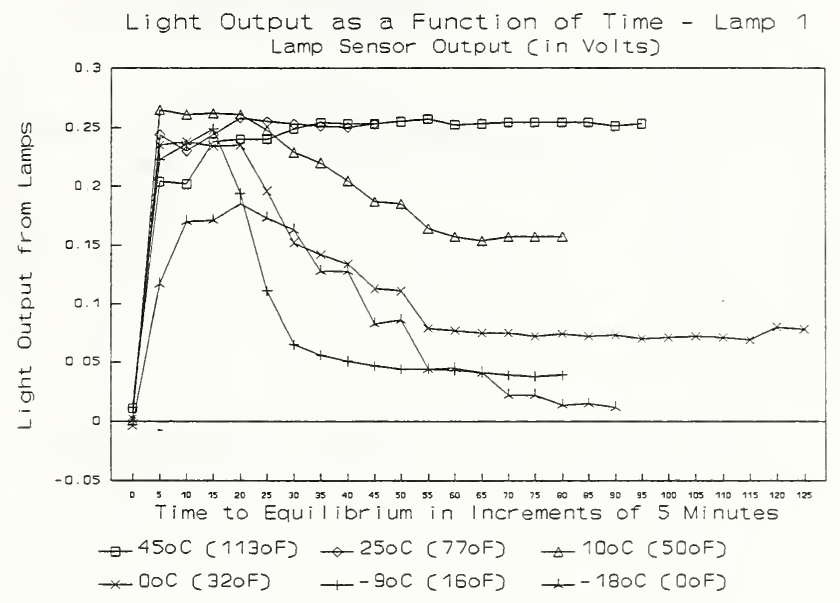

Relative Light Output as a Function of Time - Lamp 1 Light Output Relative to Equilibrium Value

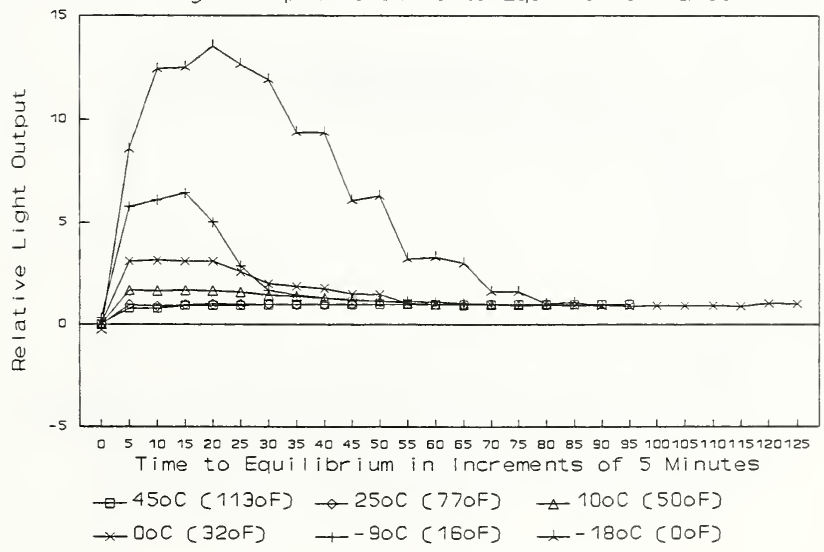


Figure 2. Time to Equilibrium and Relative Light Output for Lamp 2.
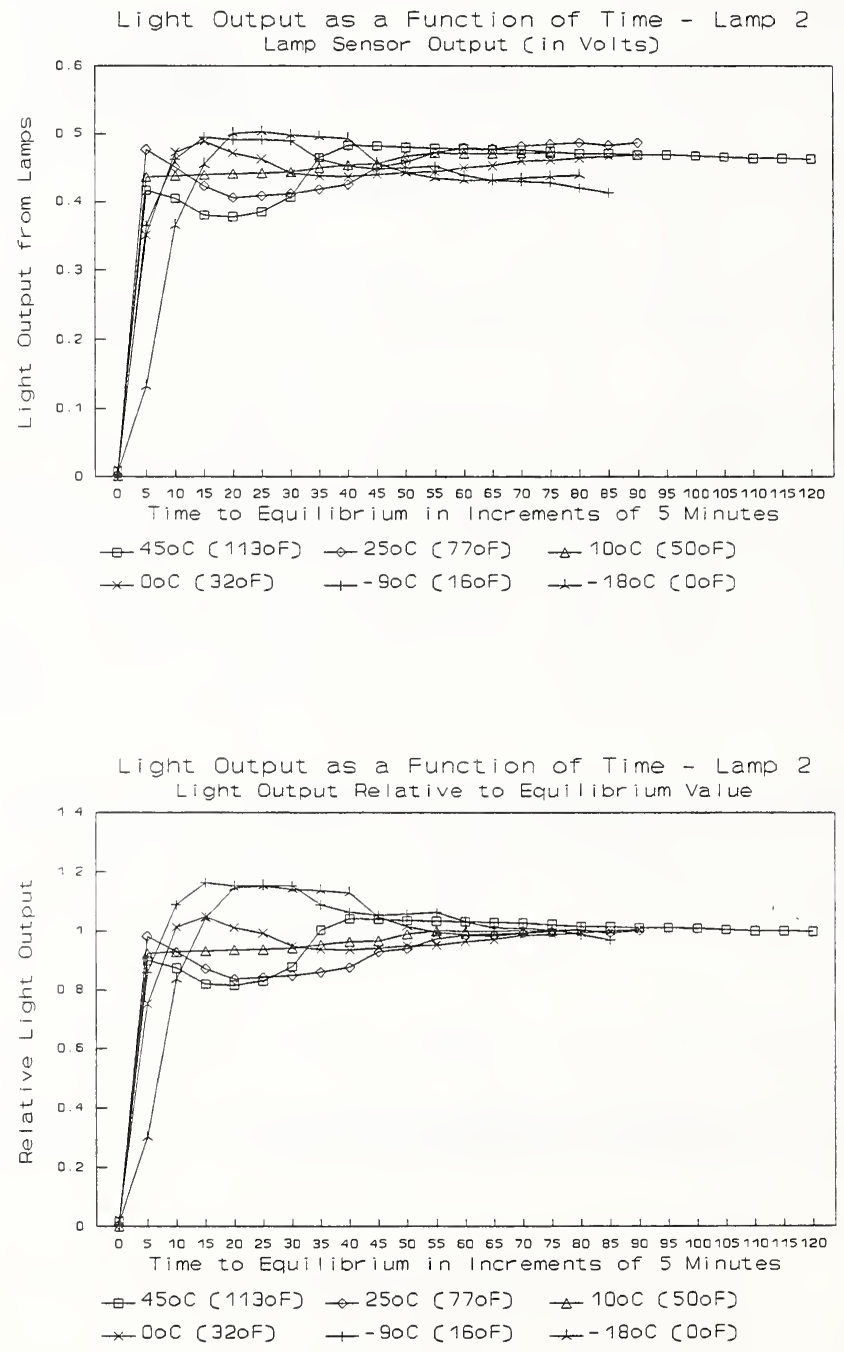
Figure 3. Time to Equilibrium and Relative Light Output for Lamp 3.

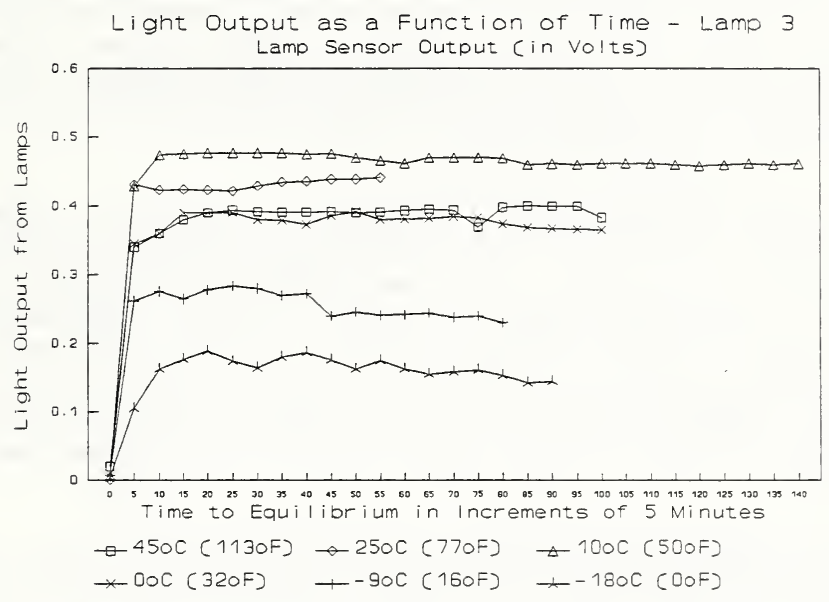

Light Output as a Function of Time - Lamp 3 Light Output Relative to Equilibrium Value

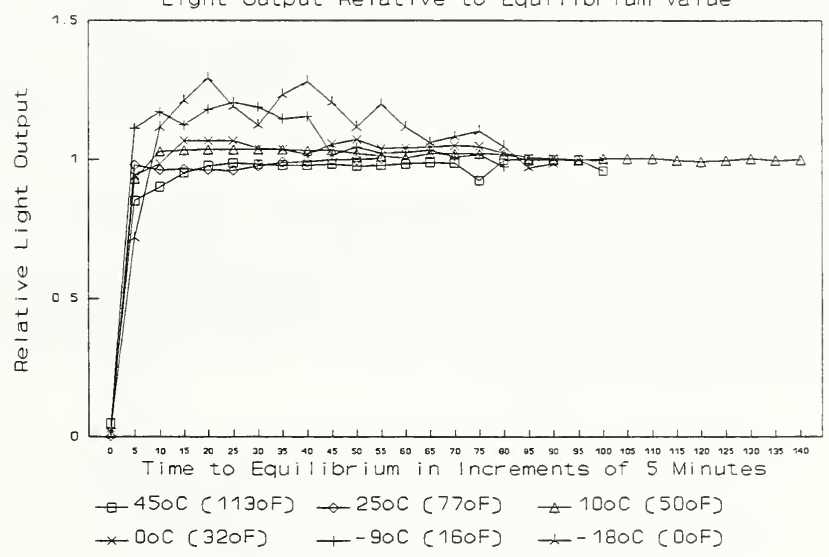


Figure 4 demonstrates much less decline in light output for lamp 4 than for lamp 3 as a function of time and ambient temperature. For most of the ambient temperatures, light output was relatively constant after about 30 to 60 minutes. At $-18^{\circ} \mathrm{C}$, however, there was a noticeable decline in light output after about an hour at that temperature. Figure 4 suggests that light output for lamp 4 reached an early peak, dropped back and then increased for the coldest and warmest temperatures. Light output for this set of lamps [which also had a surrounding globe] appeared relatively unaffected by temperature.

On the other hand, luminous output for lamp 5, as shown in figure 5, was noticeably reduced at the two coldest temperatures, with an initially higher output followed by a decline after about 20 to 30 minutes at -9 and $-18^{\circ} \mathrm{C}$. One of the lamps (C) in set 5 actually failed at these temperatures. At temperatures above $-9^{\circ} \mathrm{C}$, light output from these lamps tended to reach an equilibrium relatively rapidly and maintain it, however as shown by Figure 5b. Figure 6 displays the response of these same lamps when they were placed in an enclosure. The surrounding globe apparently insulated them from the effects of the colder ambient temperatures since light output for lamp 6 was higher at both $-9^{\circ}$ and $-18^{\circ} \mathrm{C}$ and was more stable over time, than for lamp 5.

The lower plot in figure 7 indicates that lamp 7 tended to reach equilibrium early, with relatively little fluctuation in output over time. The upper plot (7a) demonstrates a marked decline in light output as temperature deviated from $25^{\circ} \mathrm{C}$, however. (It should be pointed out that the data for the three lower curves represent the output of only two lamps since one was broken during the setup for $0^{\circ}$ ). Nonetheless, light output was noticeably diminished for these two lamps at the coldest temperatures with reduced output apparent even at $10^{\circ} \mathrm{C}$.

Figure 8 indicates that lamp 8 experienced marked decline in light output at $0^{\circ} \mathrm{C}$ and complete failure at temperatures below $0^{\circ} \mathrm{C}$. Unlike many of the other lamps, light output for these lamps was actually lower at $25^{\circ} \mathrm{C}$ than at 10 or $45^{\circ} \mathrm{C}$. Light output increased at $10^{\circ} \mathrm{C}$ for the first minutes, before returning to values similar to those at $45^{\circ} \mathrm{C}$. This lamp contained a constant illumination circuit which appears to have been effective at the higher temperatures.

Figure 9 demonstrates that some rather strange temperature effects occurred for lamp 9 with a marked decline in output for the two coldest temperatures and a late drop in output at the warmest temperature $\left(45^{\circ} \mathrm{C}\right)$ about 90 minutes into the test period. This sudden drop in the last four data points appears to be an unanticipated, delayed response to thermal stress. Colder temperatures markedly reduced light output for this set of lamps with an output at $-18^{\circ} \mathrm{C}$ of only about $20 \%$ of that at $10^{\circ} \mathrm{C}$, for example. 
Figure 4. Time to Equilibrium and Relative Light Output for Lamp 4.

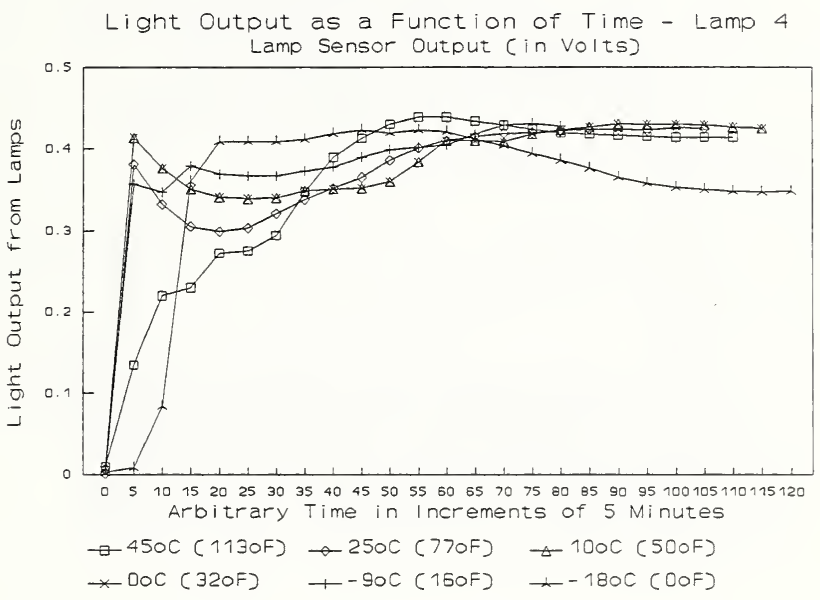

Light Output as a Function of Time - Lamp 4 Light Output Relative to Equilibrium value

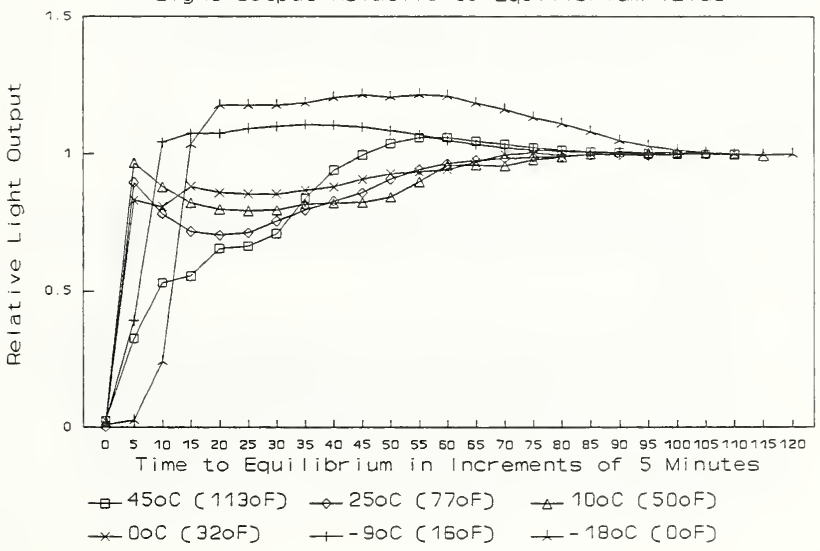


Figure 5. Time to Equilibrium and Relative Light Output for Lamp 5.

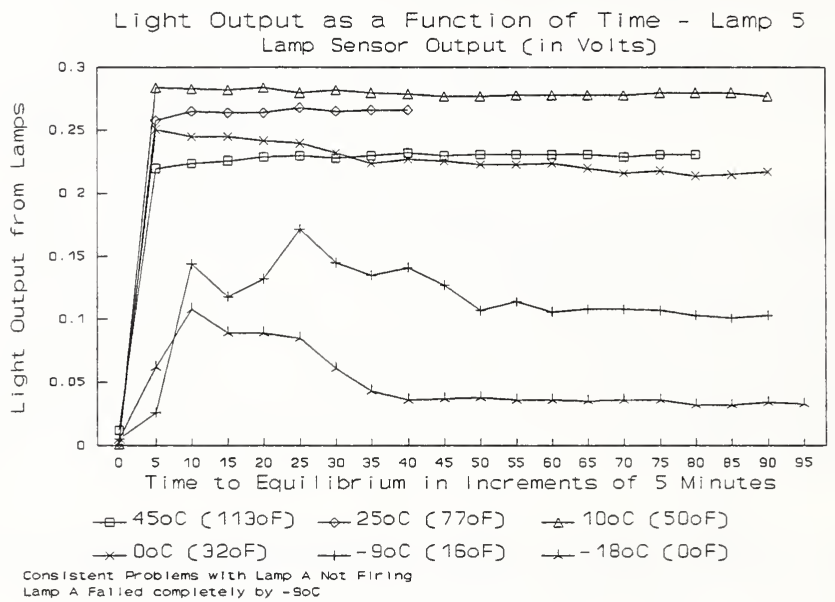

Light Output as a Function of Time - Lamp 5 Light Output Relative to Equilibrium Value

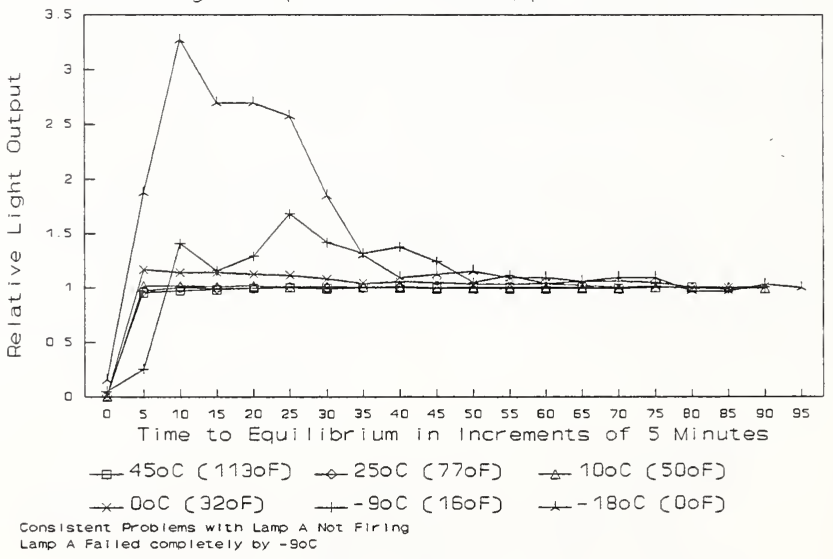


Figure 6. Time to Equilibrium and Relative Light Output for Lamp 6.
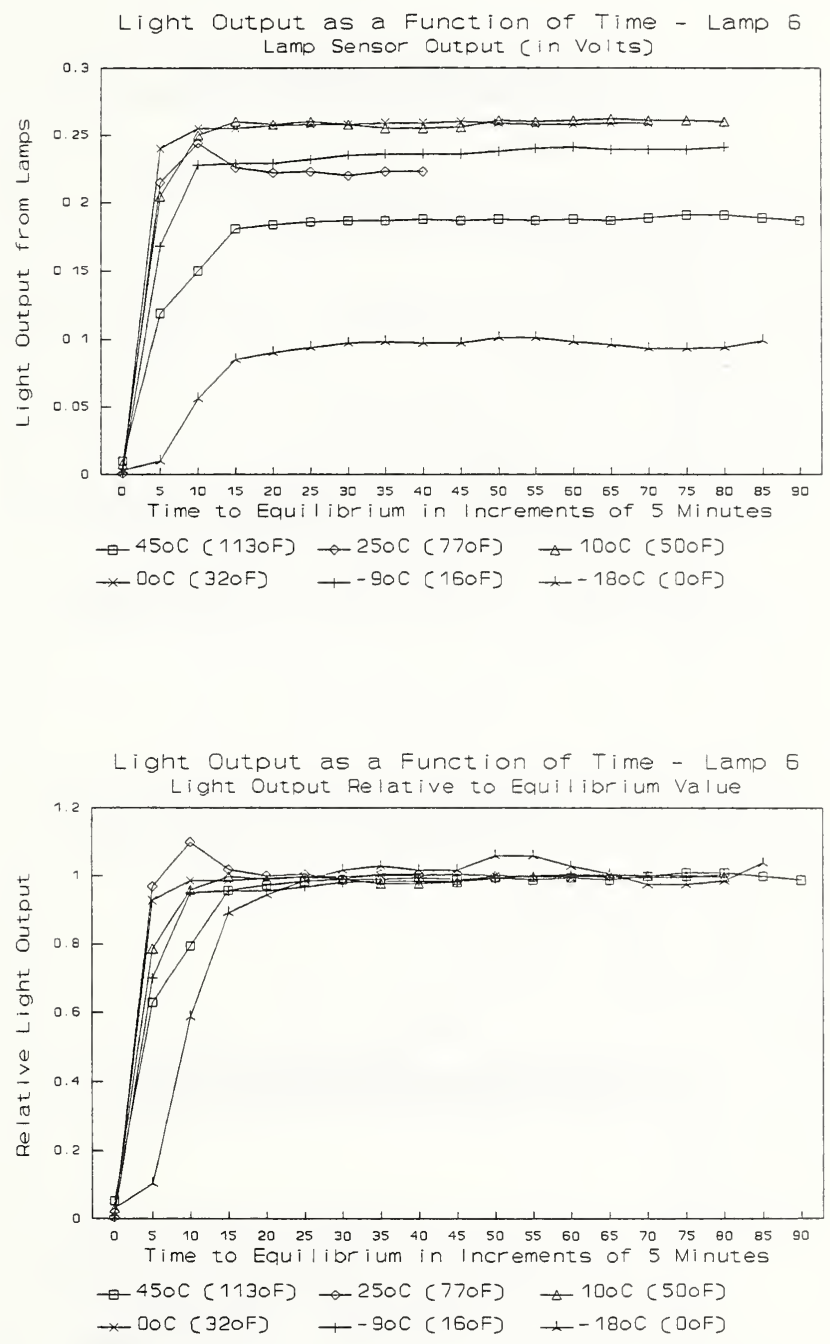
Figure 7. Time to Equilibrium and Relative Light Output for Lamp 7.
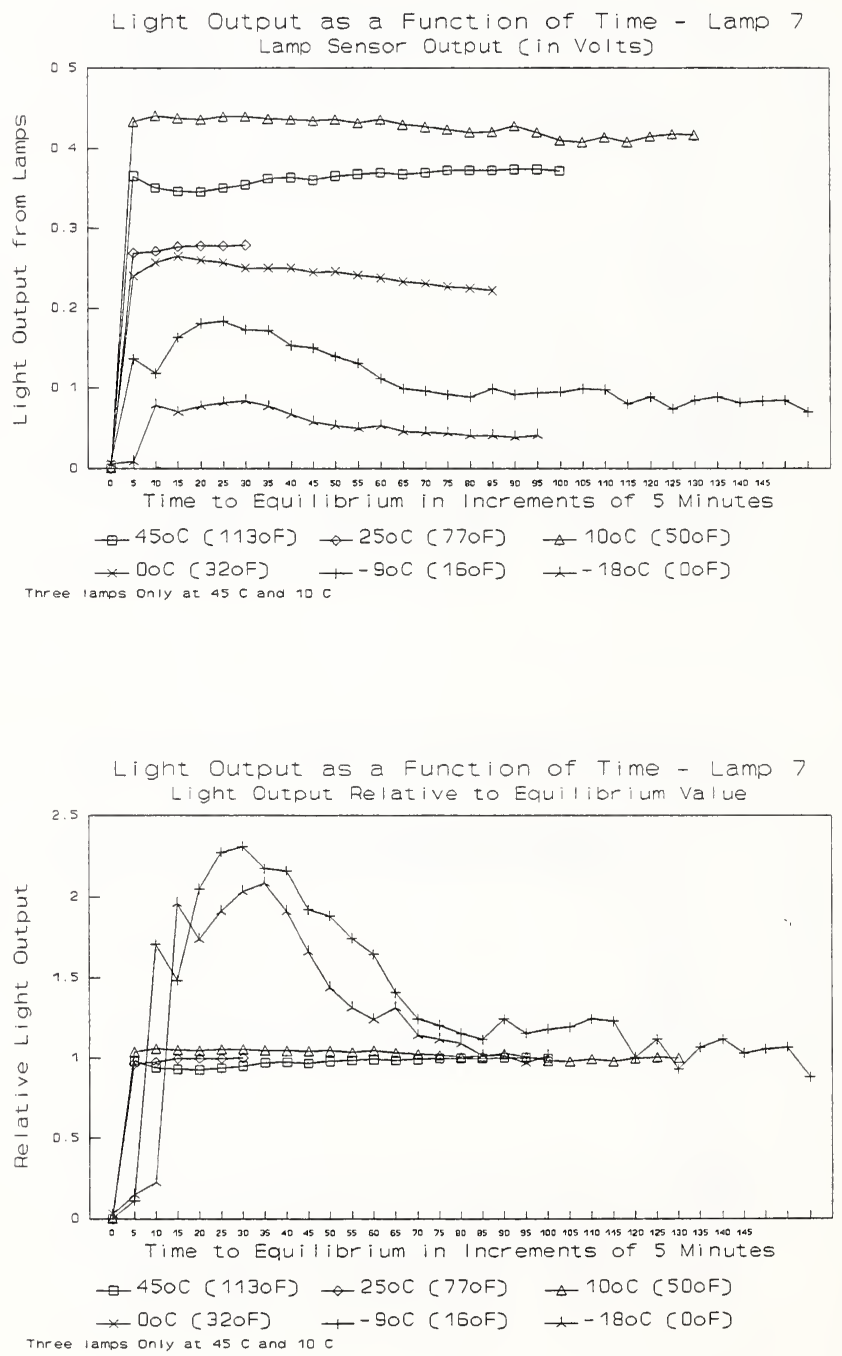
Figure 8. Time to Equilibrium and Relative Light Output for Lamp 8.

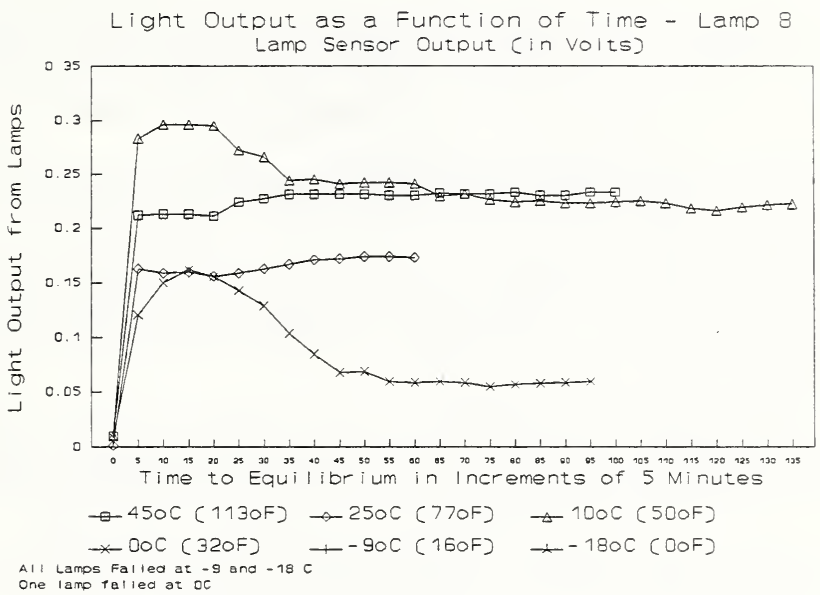

Light Output as a Function of Time - Lamp 8 Light Output Relative to Equilibrium value

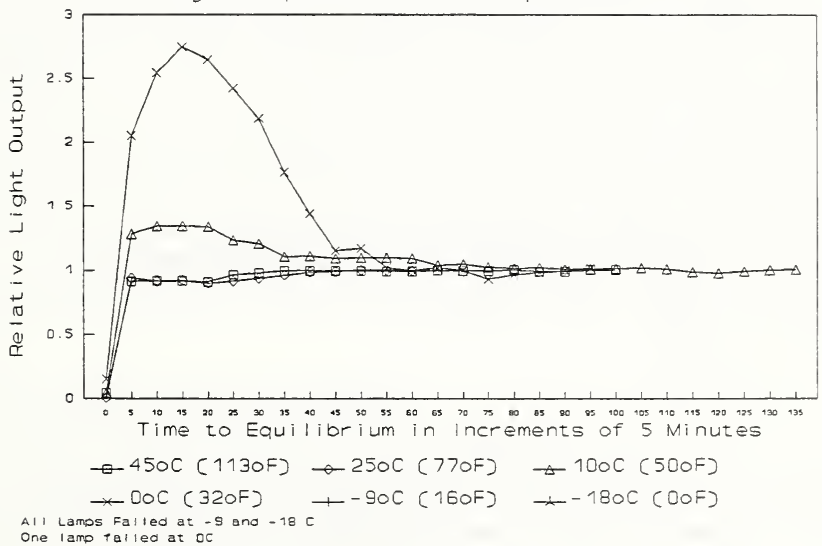

One lamp tefled at oC 
Figure 9. Time to Equilibrium and Relative Light Output for Lamp 9.

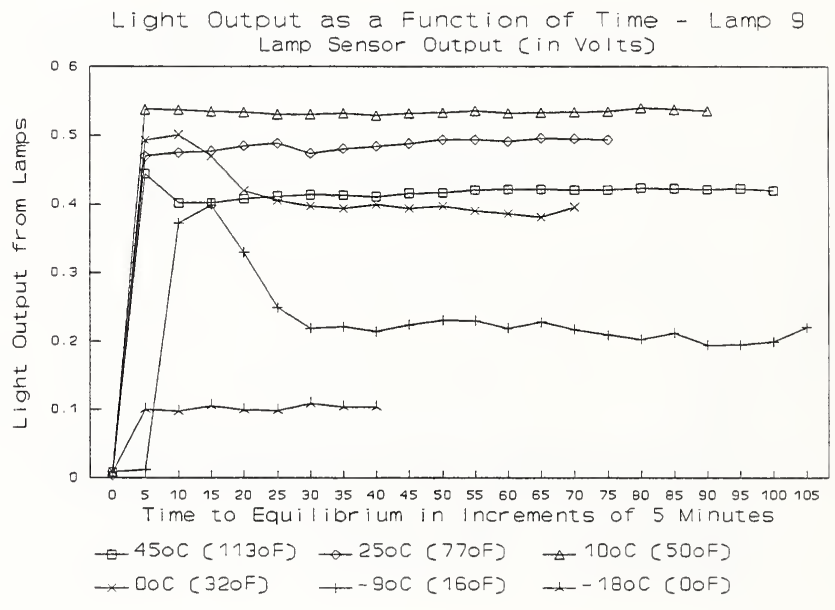

Light Output as a Function of Time - Lamp 9 Light Output Relative to Equilibrium Value

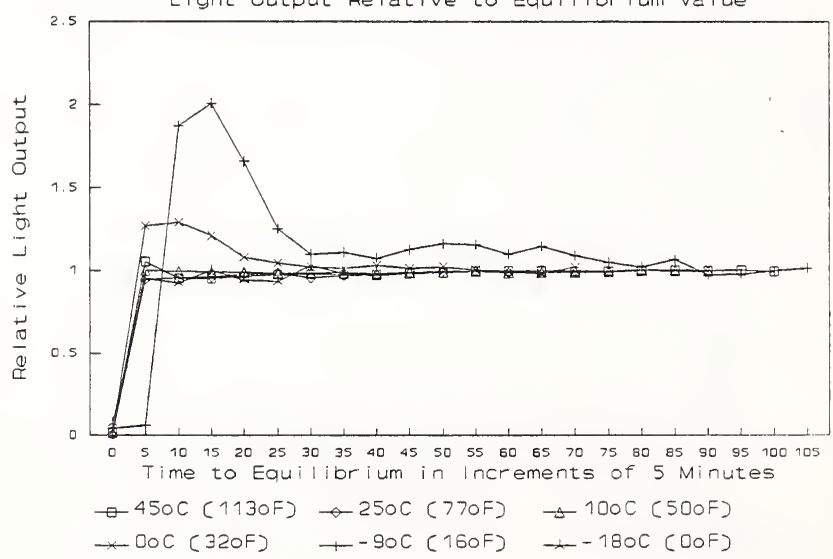


Figure 10 shows that light output for lamp 10 was also reduced at the lowest two temperatures, with output at $-9^{\circ} \mathrm{C}$ initially being the same as that at $45^{\circ} \mathrm{C}$, but then immediately falling off to about $60 \%$ of the output, and that at $-18^{\circ} \mathrm{C}$ steadily declining after the first five minutes and reaching a final value of about $15 \%$ of that at the baseline condition. Output at $45^{\circ} \mathrm{C}$ was actually slightly below that at $0^{\circ} \mathrm{C}$, although there was greater variability in the time to equilibrium for the latter. Relative light output was reasonably stable after 5 to 15 minutes of operation for temperatures above $-9^{\circ} \mathrm{C}$, however.

As with lamp 9, lamp 11 also displayed a peculiar drop in light output at $45^{\circ} \mathrm{C}$ at the end of the test period as can be seen in figure 11. Before that, light output values for the four warmest temperatures were comparable, with only the data for $0^{\circ} \mathrm{C}$ declining slightly over time. Inspection of the upper plot suggests that the light output peaked early and then declined over time, but never really reached equilibrium at -9 and $-18{ }^{\circ} \mathrm{C}$. Figure 12 shows relatively little effect of temperature on time to equilibrium or light output for the incandescent lamp, lamp 13.

Comparable data were not available for the low voltage lamp, lamp 12, which experienced numerous electrical problems throughout the course of data collection. All lamps in this system failed to ignite at temperatures below $0^{\circ} \mathrm{C}$. As a result, their data were not graphed.

An overview of the twelve figures demonstrates that most of the lamps evaluated were markedly affected by temperature extremes, displaying noticeable reductions in light output at the colder temperatures with frequent reductions to $10-20 \%$ or less of their output at the baseline $25^{\circ} \mathrm{C}$ temperature. In addition, lamps $1,3,5$ (and 6), 7, 8, 9, 10 and 11 showed great variability in time to equilibrium. Light output and time to equilibrium were reduced for lamp 1 at $10^{\circ} \mathrm{C}$, while lamps 5,9 , and 10 displayed reduced output at $45^{\circ} \mathrm{C}$. Addition of extra humidity, by using a fine mist at $-4^{\circ} \mathrm{C}$ caused lamps 4,5 , and 8 to fail to ignite. Of course, lamp 8 failed outright at $-9^{\circ} \mathrm{C}$. Only lamps 2 and 4 , which had external globes, were relatively unaffected by the colder temperature extremes. Light output for these two lamps was reduced at the two warmer temperatures $\left(25^{\circ}\right.$ and $\left.45^{\circ} \mathrm{C}\right)$, however. While lamp 4 contained an integral electronic ballast, so did lamp 3 which demonstrated much greater temperature sensitivity than lamp 4 . These data suggest that presence of an enclosure, or globe, improved performance at colder temperatures as indicated by the results for lamps 2 and 4 . Even the poor performance of lamp 5 at low temperatures was improved by the addition of an enclosure, as can be seen from the data for lamp 6. In contrast, presence of a globe appeared to reduce light output at the warmest temperatures. Nonetheless, temperature extremes, both low and high, reduced overall light output and increased the time to luminous equilibrium for almost all the compact fluorescent lamps studied.

\subsection{Lamp Performance Data at Equilibrium}

Table 2 summarizes the lamp performance data obtained at the end of the test when the lamps had achieved equilibrium. This table presents data on time to ignition (in seconds), time to luminous equilibrium (in minutes), temperature at the bottom tip on each of the three lamps, flicker index, lamp luminance (in $\mathrm{cd} / \mathrm{m}^{2}$ ), lamp light output (in nominal volts), luminous efficacy (in $\mathrm{cd} / \mathrm{m}^{2} /$ watts), relative luminous efficacy (relative to performance at $25^{\circ} \mathrm{C}$ ), lamp input power in watts and volt amps, power factor, total harmonic distortion (for voltage and current), input 
Figure 10. Time to Equilibrium and Relative Light Output for Lamp 10.

Light Output as a Function of Time - Lamp 10 Lamp Sensor Output (in Volts)

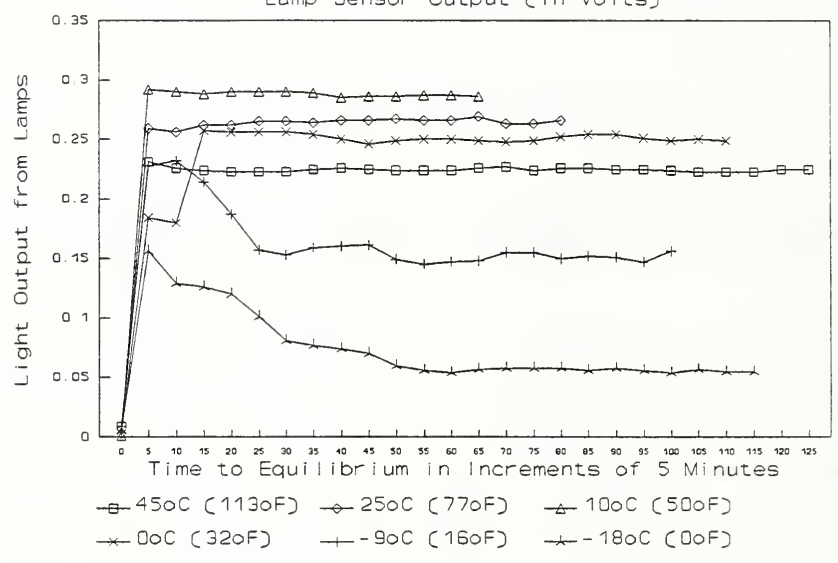

Light Output as a Function of Time - Lamp 10 Light Output Relative to Equilibrium Value

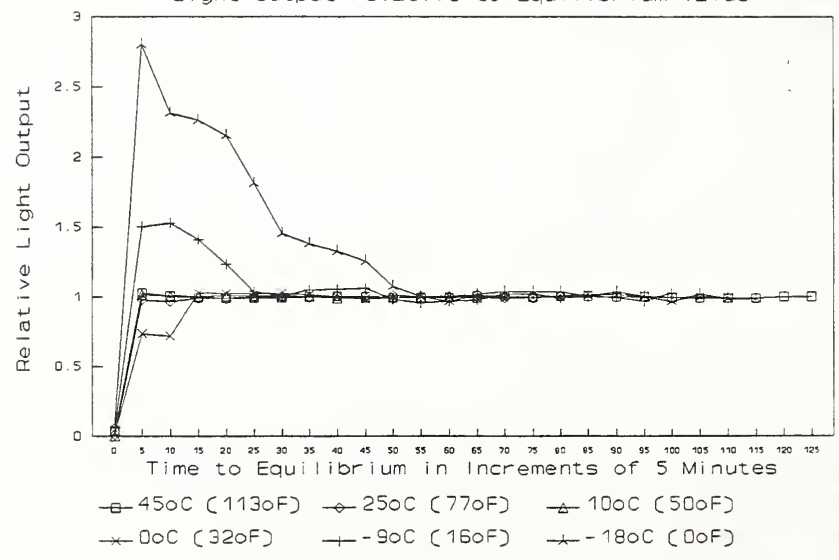


Figure 11. Time to Equilibrium and Relative Light Output for Lamp 11.

Light Output as a Function of Time - Lamp 11 Lamp Sensor Output (in volts)

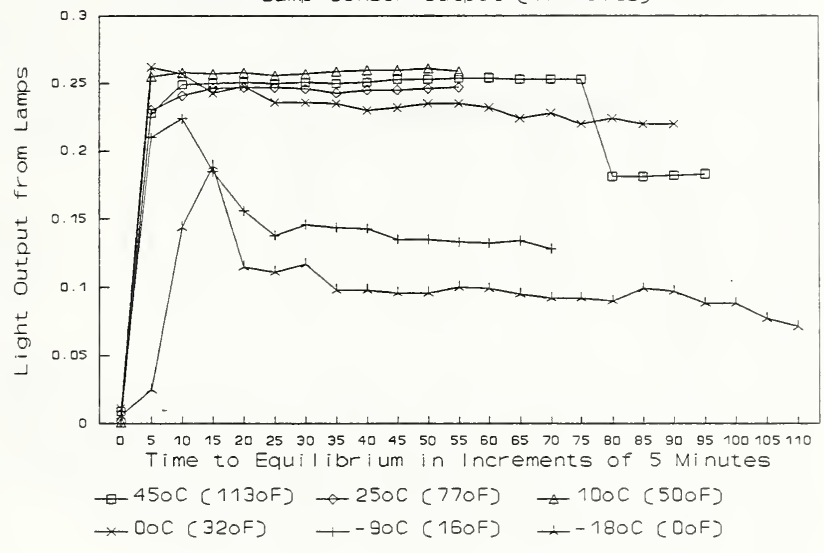

Light Output as a Function of Time - Lamp 11

Light Output Relative to Equilibrium Value

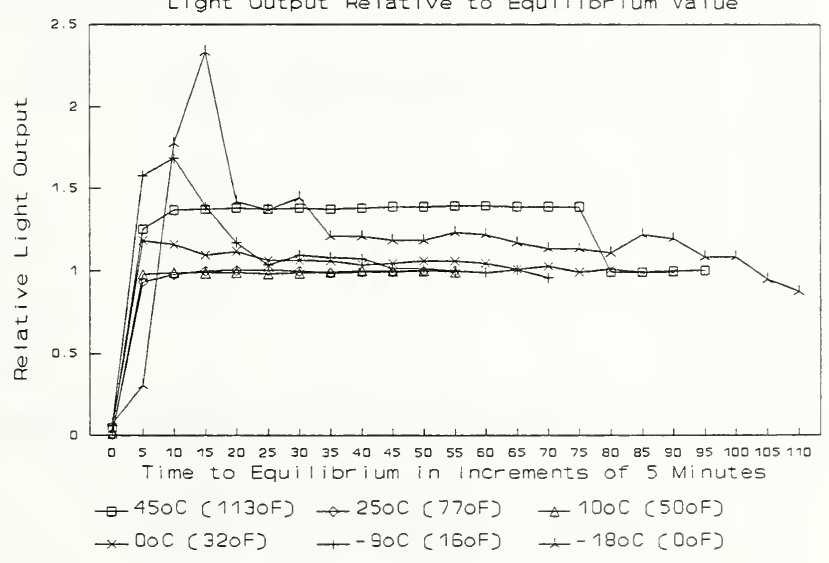


Figure 12. Time to Equilibrium and Relative Light Output for Lamp 13.

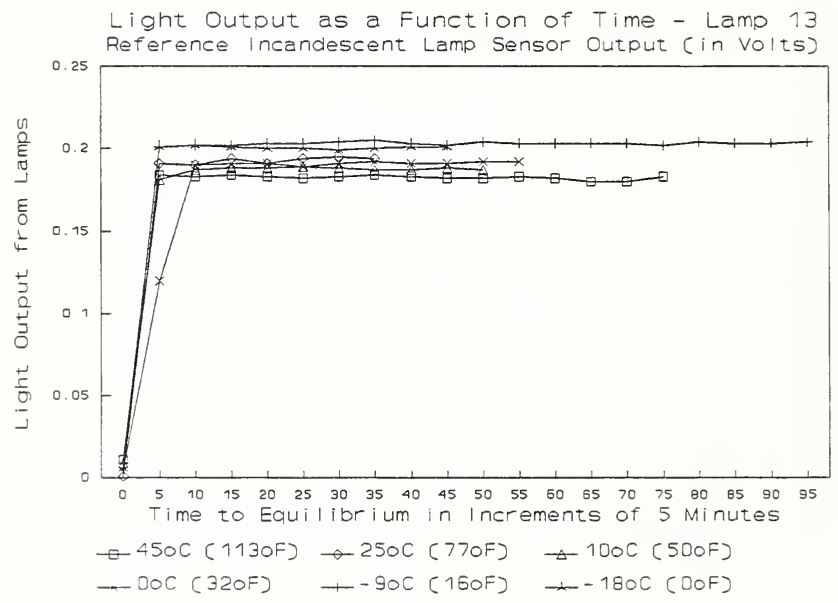

Light Output as a Function of Time - Lamp 13 incandescent Lamp Output Relative to Equilibrium Value

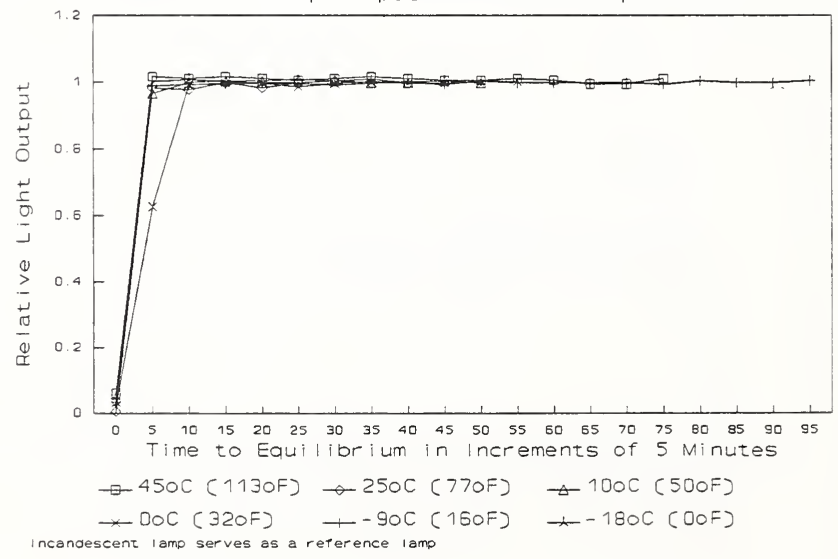


Table 2. Summary of Test Results for Each Lamp Set as a Function of Ambient Temperature

Lamp 1

\begin{tabular}{lccrrrrr}
${ }^{\circ} \mathrm{C}$ Ambient & 45 & 25 & $25 \mathrm{R}$ & 10 & 0 & -9 & -18 \\
\hline & & & & & & & \\
Time to Ignite (Sec) & 2.5 & 3.0 & 3.0 & 3.5 & 3.0 & 3.0 & 25.0 \\
Time to Equil (Min) & 44.0 & 35.0 & 39.0 & 74.0 & 100.0 & 75.0 & 84.0 \\
Temp Lamp A ( ${ }^{\circ} \mathrm{C}$ ) & 51.1 & 36.9 & 39.7 & 22.5 & 13.4 & 1.1 & -16.8 \\
Temp Lamp B & 54.3 & 40.0 & 39.0 & 23.1 & 18.2 & 2.1 & -7.4 \\
Temp Lamp C & 48.7 & 37.7 & 35.9 & 23.2 & 13.5 & 0.3 & -9.2 \\
Flicker Index & 0.12 & 0.11 & & 0.12 & 0.15 & 0.16 & \\
Lamp Lum (cd/m ${ }^{2}$ ) & 18.0 & 18.0 & 18.1 & 9.9 & 4.5 & 2.1 & 0.9 \\
Lamp Volts & 0.25 & 0.25 & 0.25 & 0.16 & 0.07 & 0.04 & 0.01 \\
Power (Watts) & 56.4 & 54.1 & 54.3 & 53.9 & 52.6 & 49.9 & 48.7 \\
& & & & & & & 0.01 \\
LumEff (cd/m ${ }^{2} /$ Watts) & 0.09 & 0.10 & 0.10 & 0.05 & 0.02 & 0.01 & 0.01 \\
Relative LumEff & 0.96 & 1.00 & 1.00 & 0.55 & 0.25 & 0.13 & 0.06 \\
& & & & & & & \\
Power (Volt/amps) & 113.7 & 106.8 & 107.0 & 114.0 & 118.2 & 115.2 & 126.6 \\
Power Factor & 0.50 & 0.51 & 0.51 & 0.47 & 0.45 & 0.43 & 0.38 \\
THD Voltage & 3.7 & 3.7 & 3.7 & 3.7 & 3.7 & 3.7 & 3.5 \\
THD Current & 11.7 & 12.7 & 12.5 & 11.3 & 11.0 & 11.3 & 14.1 \\
Input Voltage & 121.4 & 121.3 & 121.6 & 121.3 & 121.5 & 121.6 & 121.5 \\
Current & 930.0 & 865.0 & 880.0 & 939.0 & 972.0 & 948.0 & 1042.0 \\
Burn Time & 99.0 & 106.0 & 44.0 & 80.0 & 118.0 & 81.0 & 91.0
\end{tabular}

Lamp 2

\begin{tabular}{lccccccc}
${ }^{\circ}$ C Ambient & 45 & 25 & $25 \mathrm{R}$ & 10 & 0 & -9 & -18 \\
\hline Time to Ignite (Sec) & 2.0 & 2.5 & 3.0 & 3.0 & 5.0 & 6.0 & 11.0 \\
Time to Equil (Min) & 84.0 & 110.0 & 75.0 & 55.0 & 72.0 & 70.0 & 63.0 \\
Temp Lamp A ( ${ }^{\circ} \mathrm{C}$ ) & 61.8 & 44.6 & 44.2 & 30.0 & 21.6 & 14.4 & 2.7 \\
Temp Lamp B & 49.0 & 44.1 & 42.4 & 28.6 & 21.5 & 10.8 & 2.3 \\
Temp Lamp C & 62.4 & 43.6 & 43.5 & 31.2 & 20.1 & 12.2 & 5.1 \\
Flicker Index & 0.06 & 0.05 & & 0.06 & 0.06 & 0.05 & \\
Lamp Lum (cd/m ${ }^{2}$ ) & 33.9 & 36.3 & 34.5 & 34.3 & 33.9 & 29.5 & 31.9 \\
Lamp Output (volts) & 0.47 & 0.49 & 0.49 & 0.47 & 0.46 & 0.43 & 0.43 \\
Power (Watts) & 52.0 & 52.1 & 51.9 & 52.2 & 51.8 & 50.9 & 51.4 \\
& & & & & & & \\
LumEff (cd/m ${ }^{2} /$ Watts) & 0.19 & 0.20 & 0.19 & 0.19 & 0.19 & 0.17 & 0.18 \\
Relative LumEff & 0.94 & 1.00 & 0.95 & 0.94 & 0.94 & 0.83 & 0.89 \\
& & & & & & & \\
Power (Volt/amps) & 94.5 & 95.1 & 95.2 & 98.2 & 99.5 & 94.8 & 92.2 \\
Power Factor & 0.55 & 0.54 & 0.54 & 0.53 & 0.52 & 0.54 & 0.53 \\
THD Voltage & 3.8 & & 3.8 & 3.5 & 3.7 & 3.7 & 3.8 \\
THD Current & 11.2 & & 11.0 & 10.9 & 10.2 & 11.3 & 11.0 \\
Input Voltage & 121.5 & 121.7 & 121.8 & 121.7 & 121.9 & 121.9 & 121.7 \\
Current & 767.0 & 781.4 & 782.0 & 798.0 & 816.0 & 778.0 & 791.0 \\
Burn Time (min) & 122.0 & 171.0 & 85.0 & 115.0 & 87.0 & 86.0 & 113.0
\end{tabular}


Lamp 3

\begin{tabular}{lcccccrr}
${ }^{\circ} \mathrm{C}$ Ambient & 45 & 25 & $25 \mathrm{R}$ & 10 & 0 & -9 & -18 \\
\hline Time to Ignite (Sec) & 1.5 & 0.5 & 2.0 & 1.5 & 2.0 & 2.0 & 3.0 \\
Time to Equil (Min) & 82.0 & 49.0 & 40.0 & 76.0 & 89.0 & 60.0 & 89.0 \\
Temp Lamp A ( ${ }^{\circ}$ ) & 45.2 & 54.2 & 52.8 & 39.2 & 24.4 & 18.4 & 1.7 \\
Temp Lamp B & 45.6 & 58.4 & 52.3 & 38.0 & 27.0 & 20.7 & 13.8 \\
Temp Lamp C & 46.3 & 46.2 & 51.6 & 40.6 & 37.0 & 16.3 & 8.8 \\
Flicker Index None & & & & & & & \\
Lamp Lum (cd/m ${ }^{2}$ ) & 28.2 & 28.4 & 32.1 & 32.6 & 26.0 & 16.0 & 10.5 \\
Lamp output (volts) & 0.40 & 0.41 & 0.44 & 0.47 & 0.37 & 0.24 & 0.15 \\
Power (watts) & 48.1 & 53.3 & 55.4 & 56.9 & 55.9 & 51.9 & 50.6 \\
& & & & & & & 0.06 \\
LumEff (cd/m $/$ Watts) & 0.17 & 0.16 & 0.17 & 0.17 & 0.14 & 0.09 & 0.06 \\
Relative LumEff & 1.10 & 1.00 & 1.09 & 1.08 & 0.88 & 0.58 & 0.39 \\
& & & & & & & \\
Power (Volt/amps) & 70.4 & 99.1 & 80.5 & 82.9 & 81.5 & 76.2 & 74.2 \\
Power Factor & 0.68 & 0.68 & 0.69 & 0.69 & 0.69 & 0.68 & 0.68 \\
THD Voltage & 4.6 & & 4.4 & 4.4 & 4.5 & 4.5 & 4.5 \\
THD Current & 102.2 & & 100.9 & 100.8 & 101.2 & 102.1 & 102.6 \\
Input Voltage & 122.4 & 122.9 & 122.9 & 122.6 & 122.4 & 122.5 & 122.5 \\
Input Current & 402.0 & 633.0 & 655.0 & 676.0 & 666.0 & 622.0 & 606.0 \\
Burn Time (Min) & 97.0 & 76.0 & 65.0 & 146.0 & 100.0 & 83.0 & 99.0
\end{tabular}

Lamp 4

\begin{tabular}{|c|c|c|c|c|c|c|c|}
\hline Ambient & 45 & 25 & $25 \mathrm{R}$ & 10 & 0 & -9 & -18 \\
\hline Time to Ignite (Sec) & 1.5 & 2.0 & 3.5 & 3.0 & 5.0 & 5.0 & 5.0 \\
\hline Time to Equil (Min) & 94.0 & 165.0 & 90.0 & 85.0 & 79.0 & 95.0 & 109.0 \\
\hline Temp Lamp $A\left({ }^{\circ} \mathrm{C}\right)$ & 59.5 & 42.8 & 27.8 & 28.4 & 17.9 & 10.4 & 0.0 \\
\hline Temp Lamp B & 59.3 & 41.5 & 44.1 & 31.8 & 20.6 & 11.0 & 3.4 \\
\hline Temp Lamp C & 61.6 & 45.3 & 43.8 & 31.1 & 21.4 & 9.9 & \\
\hline Flicker Index & None & & & & & & \\
\hline Lamp Lum $\left(\mathrm{cd} / \mathrm{m}^{2}\right)$ & 29.6 & 29.5 & 30.5 & 29.8 & 29.8 & $27: 9$ & 24.9 \\
\hline Lamp output (volts) & 0.42 & 0.43 & 0.42 & 0.43 & 0.43 & 0.40 & 0.35 \\
\hline LumEff $\left(\mathrm{cd} / \mathrm{m}^{2} /\right.$ Watts $)$ & 0.15 & 0.15 & 0.16 & 0.15 & 0.15 & 0.14 & 0.13 \\
\hline Relative LumEff & 1.01 & 1.00 & 1.05 & 1.03 & 1.04 & 0.97 & 0.89 \\
\hline Power (watts) & 58.15 & 58.3 & 57.28 & 57.3 & 56.71 & 56.64 & 55.56 \\
\hline Power (Volt/amps) & 107.3 & 107.6 & 105.8 & 106.2 & 105.3 & 105.0 & 103.0 \\
\hline Power Factor & 0.54 & 0.55 & 0.54 & 0.54 & 0.54 & 0.54 & 0.54 \\
\hline THD Voltage & 4.4 & 4.5 & 4.4 & 4.5 & 4.4 & 4.4 & 4.4 \\
\hline THD Current & 138.1 & 138.5 & 138.6 & 139.4 & 139.5 & 139.2 & 139.2 \\
\hline Input Voltage & 122.4 & 122.5 & 122.6 & 122.6 & 122.6 & 122.5 & 122.7 \\
\hline Input Current & 515.0 & 513.0 & 863.0 & 866.0 & 859.0 & 857.0 & 839.0 \\
\hline Burn Time (min) & 140.0 & 276.0 & 49.0 & 116.0 & 87.0 & 100.0 & 115.0 \\
\hline
\end{tabular}


Lamp 5 (Experienced Problems with Lamp C)

\begin{tabular}{|c|c|c|c|c|c|c|c|c|}
\hline Ambient & 45 & 25 & $25 \mathrm{R}$ & 10 & 0 & -9 & -18 & $\begin{array}{l}5 B \& C \\
25-2 \\
\end{array}$ \\
\hline Time to Ignite (sec) & 5.0 & 5.0 & 7.0 & 4.5 & 6.5 & 25.0 & 205.0 & 5.0 \\
\hline Time to Equil (min) & 24.0 & 22.0 & 14.0 & 49.0 & 74.0 & 78.0 & 76.0 & 14.0 \\
\hline Temp Lamp A $\left({ }^{\circ} \mathrm{C}\right)$ & 57.8 & 53.9 & 48.7 & 41.0 & 30.5 & 15.7 & & 24.8 \\
\hline Temp Lamp B & 65.0 & 54.6 & 52.2 & 41.3 & 35.8 & 18.7 & 9.9 & 52.2 \\
\hline Temp Lamp C & 64.9 & 35.3 & 49.3 & 34.5 & 29.6 & 13.3 & 4.1 & 49.1 \\
\hline Flicker Index & 0.12 & 0.15 & & 0.12 & 0.10 & 0.14 & & \\
\hline Lamp Lum $\left(\mathrm{cd} / \mathrm{m}^{2}\right)$ & 15.8 & 16.9 & 19.3 & 18.9 & 15.3 & 6.8 & 2.1 & 14.1 \\
\hline Lamp Volts & 0.23 & 0.23 & 0.26 & 0.28 & 0.22 & 0.10 & 0.03 & 0.19 \\
\hline Power (watts) & 48.5 & 47.8 & 47.9 & 46.1 & 46.5 & 45.2 & 29.0 & 32.6 \\
\hline LumEff $\left(\mathrm{cd} / \mathrm{m}^{2} /\right.$ Watts $)$ & 0.10 & 0.10 & 0.12 & 0.12 & 0.10 & 0.04 & 0.02 & 0.13 \\
\hline Relative LumEff & 0.81 & 0.88 & 1.00 & 1.02 & 0.82 & 0.37 & 0.18 & 1.08 \\
\hline Power (Volt/amps) & 91.4 & 85.8 & 85.14 & 80.18 & 84.14 & 90.36 & 59.24 & 58.7 \\
\hline Power Factor & 0.5 & 0.56 & 0.56 & 0.58 & 0.55 & 0.50 & 0.49 & 0.56 \\
\hline THD Voltage & 3.7 & & 3.8 & 3.8 & 3.8 & 3.8 & 4.0 & 3.9 \\
\hline THD Current & 8.2 & & 10.1 & 11.7 & 10.7 & 8.9 & 9.4 & 10.2 \\
\hline Input Voltage & 121.8 & 121.8 & 121.8 & 121.8 & 122.0 & 121.7 & 122.2 & 122.1 \\
\hline Input Current & 747.0 & 704.0 & 699.0 & 659.0 & 690.0 & 743.0 & 485.0 & 481.0 \\
\hline Burn Time (min) & 85.0 & 76.0 & 70.0 & 90.0 & 90.0 & 83.0 & 91.0 & \\
\hline
\end{tabular}

Lamp 6 (Experienced problems with Lamp C)

\begin{tabular}{|c|c|c|c|c|c|c|c|}
\hline Ambient & 45 & 25 & $25 \mathrm{R}$ & 10 & 0 & -9 & -18 \\
\hline Time to Ignite (sec) & 5.0 & 6.0 & 6.0 & 5.0 & 5.0 & 25.0 & 451.0 \\
\hline Time to Equil (min) & 29.0 & 35.0 & 25.0 & 23.0 & 25.0 & 59.0 & 76.0 \\
\hline Temp Lamp A $\left({ }^{\circ} \mathrm{C}\right)$ & 48.8 & 31.4 & 30.7 & 17.3 & 7.9 & -1.3 & -17.8 \\
\hline Temp Lamp B & 47.3 & 30.5 & 31.1 & 17.8 & 7.8 & -0.7 & -10.3 \\
\hline Temp Lamp C & 49.3 & 30.5 & 30.4 & 17.3 & 8.0 & -1.4 & -11.2 \\
\hline Flicker Index & 0.12 & 0.14 & & 0.06 & 0.10 & 0.15 & \\
\hline Lamp Lum $\left(\mathrm{cd} / \mathrm{m}^{2}\right)$ & 13.3 & 17.1 & 16.5 & 14.8 & 18.5 & 17.2 & 6.6 \\
\hline Lamp Output (volts) & 0.19 & 0.22 & 0.22 & 0.26 & 0.26 & 0.24 & 0.09 \\
\hline Power (watts) & 48.04 & 48.40 & 48.07 & 47.44 & 46.84 & 46.19 & 30.75 \\
\hline LumEff $\left(\mathrm{cd} / \mathrm{m}^{2} /\right.$ Watts $)$ & 0.08 & 0.10 & 0.10 & 0.09 & 0.12 & 0.11 & 0.06 \\
\hline Relative LumEff & 0.79 & 1.00 & 0.97 & 0.88 & 1.12 & 1.06 & 0.61 \\
\hline Power (Volt/amps) & 96.7 & 84.83 & 90.74 & 84.42 & 81.58 & 81.6 & 58.66 \\
\hline Power Factor & 0.5 & 0.54 & 0.53 & 0.56 & 0.57 & 0.57 & 0.52 \\
\hline THD Voltage & 3.8 & & 3.8 & 3.8 & 3.8 & 3.8 & 3.9 \\
\hline THD Current & 7.1 & & 8.5 & 10.1 & 11.2 & 11.6 & 9.3 \\
\hline Input Voltage & 121.6 & 121.9 & 121.7 & 121.8 & 122.0 & 122.2 & 122.1 \\
\hline Input Current & 785.0 & 742.0 & 745.0 & 694.0 & 669.0 & 668.0 & 481.0 \\
\hline Burn Time (min) & 91.0 & 386.0 & 41.0 & 77.0 & 71.0 & 79.0 & 76.0 \\
\hline
\end{tabular}




\begin{tabular}{|c|c|c|c|c|c|c|c|}
\hline Ambient & 45 & $25 \mathrm{R}$ & 10 & 0 & -9 & -18 & $25-2$ \\
\hline Time to Ignite (sec) & 3.0 & 2.5 & 4.0 & 4.0 & 5.0 & 411.0 & 3.0 \\
\hline Time to Equil (min) & 80.0 & 70.0 & 128.0 & 79.0 & 142.0 & 82.0 & 53.0 \\
\hline Temp Lamp $\mathrm{A}\left({ }^{\circ} \mathrm{C}\right)$ & 59.1 & 52.6 & 35.2 & 31.9 & 3.9 & 10.7 & 45.6 \\
\hline Temp Lamp B & 62.4 & 54.8 & 39.1 & 32.4 & 23.1 & -3.1 & 54.8 \\
\hline Temp Lamp C & 62.5 & 42.6 & 36.1 & Broken. & & & 24.6 \\
\hline Flicker Index & 0.12 & 0.11 & 0.06 & 0.16 & 0.0 & & \\
\hline Lamp Lum $\left(\mathrm{cd} / \mathrm{m}^{2}\right)$ & 27.1 & 36.0 & 28.6 & 14.7 & 5.2 & 2.6 & 20.5 \\
\hline Lamp Output (volts) & 0.37 & 0.49 & 0.42 & 0.22 & 0.08 & 0.04 & 0.28 \\
\hline Power (watts) & 93.46 & 93.39 & 92.26 & 60.95 & 58.01 & 55.41 & 61.95 \\
\hline LumEff $\left(\mathrm{cd} / \mathrm{m}^{2} /\right.$ Watts $)$ & 0.08 & 0.11 & 0.09 & 0.07 & 0.03 & 0.01 & 0.10 \\
\hline Relative LumEff & 0.75 & 1.00 & 0.80 & 0.63 & 0.23 & 0.12 & 0.86 \\
\hline Power (Volt/amps) & 165.6 & 171.4 & 168.3 & 91.97 & 90.9 & 89.82 & 92.89 \\
\hline Power Factor & 0.56 & 0.54 & 0.55 & 0.66 & 0.64 & 0.62 & 0.67 \\
\hline THD Voltage & 8.3 & 8.8 & 8.7 & 6.3 & 6.3 & 6.3 & 6.3 \\
\hline THD Current & 138.8 & 153.4 & 154.4 & 113.6 & 115.2 & 119.5 & 111.9 \\
\hline Input Voltage & 122.1 & 122.0 & 122.5 & 122.5 & 122.5 & 122.5 & 122. \\
\hline Input Current & 798.0 & 771.0 & 755.0 & 751.0 & 742.0 & 733.0 & 756. \\
\hline Burn Time (min) & 104.0 & 109.0 & 134.0 & 86.0 & 92.0 & 87.0 & 69. \\
\hline
\end{tabular}

\section{Lamp 8}

${ }^{\circ} \mathrm{C}$

Ambient

Time to Ignite (sec)

Time to Equil (min)

Temp Lamp A $\left({ }^{\circ} \mathrm{C}\right)$

Temp Lamp B

Temp Lamp C

Flicker Index

Lamp Lum $\left(\mathrm{cd} / \mathrm{m}^{2}\right)$

Lamp Output (volts)

Power (watts)

LumEff $\left(\mathrm{cd} / \mathrm{m}^{2} /\right.$ Watts $)$

Relative LumEff

Power (Volt/amps)

Power Factor

THD Voltage

THD Current

Input Voltage

Input Current

Burn Time (min)
45

0.5

35.0

52.0

54.1

52.1

0.10

16.5

0.23

100.8

$$
0.05
$$

0.96

$$
\begin{array}{r}
103.5 \\
0.98 \\
4.0 \\
10.9 \\
122.0 \\
845.0 \\
90.0
\end{array}
$$

25

2.5

50.0

42.1

43.3

41.8

0.11

17.7

0.24

104.5

$$
0.05
$$

1.00

107.3

$$
0.97
$$

4.0

11.6

122.0

869.0

57.0
0.05

1.07

$25 \mathrm{R}$

0.5

31.0

39.1

41.9

39.6

19.4

0.27

106.6

109.0

0.98

4.0

11.9

122.0

893.0
10

0.5

1.5

59.0

24.6

29.0

16.2

25.0

0.11

14.7

0.22

104.3

0.04

0.83

106.7

0.98

4.0

13.0

121.9

875.0

137.0

0

16. 2

3.7

0.06

64.9
$-9$

$44 \mathrm{~min}$

$-8.5$

$-8.5$

$-8.6$

.0 .07

0.15

0.0

0.01

29.1

$-18$

$25-2$

0.02

0.00

0.00

0.05

1.04

74.16

0.97

4.0

12.7

122.2

607.0

102.0 


\begin{tabular}{lcccccrr}
${ }^{\circ} \mathrm{C}$ Ambient & 45 & 25 & $25 \mathrm{R}$ & 10 & 0 & -9 & -18 \\
\hline & & & & & & & \\
Time to Ignite (sec) & 1.5 & 2.5 & 3.5 & 4.5 & 3.5 & 4.0 & 4.0 \\
Time to Equil (min) & 56.0 & 62.0 & 54.0 & 65.0 & 49.0 & 89.0 & 89.0 \\
Temp Lamp A ( ${ }^{\circ} \mathrm{C}$ ) & 63.0 & 58.1 & 50.8 & 32.3 & 24.8 & 20.6 & 2.0 \\
Temp Lamp B & 66.4 & 70.4 & 50.9 & 42.1 & 29.6 & 21.2 & 9.2 \\
Temp Lamp C & 67.7 & 51.6 & 49.2 & 35.9 & 19.6 & 14.5 & 5.2 \\
Flicker Index & 0.10 & 0.11 & & 0.12 & 0.12 & 0.14 & \\
Lamp Lum (cd/m ${ }^{2}$ ) & 30.8 & 33.6 & 35.6 & 36.7 & 26.8 & 14.1 & 7.3 \\
Lamp Volts & 0.42 & 0.46 & 0.49 & 0.53 & 0.39 & 0.20 & 0.10 \\
Power (watts) & 103.7 & 105.4 & 106.9 & 106.5 & 105.6 & 102.8 & 00.9 \\
& & & & & & & \\
LumEff (cd/m /Watts) & 0.09 & 0.09 & 0.10 & 0.10 & 0.07 & 0.04 & 0.02 \\
Relative LumEff & 0.93 & 1.00 & 1.05 & 1.08 & 0.80 & 0.43 & 0.23 \\
& & & & & & & \\
Power (Volt/amps) & 240.2 & 225.6 & 225.9 & 217.6 & 225.7 & 237.1 & 240.4 \\
Power Factor & 0.43 & 0.47 & 0.47 & 0.49 & 0.47 & 0.43 & 0.42 \\
THD Voltage & 3.2 & 3.3 & 3.3 & 3.3 & 3.2 & 3.1 & \\
THD Current & 8.4 & 8.4 & 9.2 & 8.1 & 7.1 & 6.7 & \\
Input Voltage & 119.9 & 120.0 & 120.1 & 120.1 & 119.9 & 119.9 & 119.7 \\
Input Current & 2010.0 & 1872.0 & 1880.0 & 1812.0 & 1882.0 & 1972.0 & 2008.0 \\
Burn Time (min) & 98.0 & 102.0 & 75.0 & 90.0 & 69.0 & 100.0 & 94.0
\end{tabular}

\section{Lamp 10}

\begin{tabular}{lcrrrrrr}
${ }^{\circ} \mathrm{C}$ Ambient & 45 & 25 & $25 \mathrm{R}$ & 10 & 0 & -9 & -18 \\
\hline & & & & & & & \\
Time to Ignite (sec) & 4.0 & 4.0 & 4.0 & 4.5 & 3.5 & 20.0 & 130.0 \\
Time to Equil (min) & 29.0 & 30.0 & 29.0 & 44.0 & 59.0 & 85.0 & 73.0 \\
Temp Lamp A ( $\left.{ }^{\circ} \mathrm{C}\right)$ & 65.9 & 57.6 & 52.9 & 39.0 & 31.2 & 15.5 & 4.1 \\
Temp Lamp B & 50.5 & 56.2 & 53.1 & 41.6 & 29.8 & 23.5 & 6.9 \\
Temp Lamp C & 74.0 & 53.9 & 50.3 & 38.9 & 33.9 & 19.4 & 12.3 \\
Flicker Index & 0.11 & 0.13 & & 0.13 & 0.12 & 0.13 & \\
Lamp Lum (cd/m ${ }^{2}$ ) & 15.9 & 17.8 & 18.9 & 19.5 & 16.9 & 10.1 & 3.5 \\
Lamp Output (volts) & 0.22 & 0.25 & 0.27 & 0.29 & 0.25 & 0.15 & 0.06 \\
Power (watts) & 60.39 & 59.17 & 57.89 & 55.95 & 55.68 & 56.83 & 54.81 \\
& & & & & & & \\
LumEff (cd/m ${ }^{2} /$ Watts) & 0.08 & 0.09 & 0.10 & 0.10 & 0.09 & 0.05 & 0.02 \\
Relative LumEff & 0.87 & 1.00 & 1.08 & 1.16 & 1.00 & 0.59 & 0.21 \\
& & & & & & & \\
Power (volt/amps) & 113.05 & 121.10 & 104.40 & 97.71 & 98.76 & 108.0 & 110.1 \\
Power Factor & 0.55 & 0.49 & 0.55 & 0.57 & 0.56 & 0.53 & 0.5 \\
THD Voltage & 3.5 & 3.7 & 3.7 & 3.8 & 3.7 & 3.8 & 3.7 \\
THD Current & 10.7 & 10.7 & 11.3 & 12.8 & 12.7 & 11.0 & 10.9 \\
Input Voltage & 121.4 & 121.6 & 121.5 & 121.7 & 121.5 & 121.6 & 121.6 \\
Input Current & 919.0 & 873.0 & 859.0 & 806.0 & 813.0 & 889.0 & 905.0 \\
Burn Time (min) & 127.0 & 85.0 & 81.0 & 65.0 & 118.0 & 101.0 & 120.0
\end{tabular}


Lamp 11

\begin{tabular}{lccrrrrr}
${ }^{\circ} \mathrm{C}$ Ambient & 45 & 25 & $25 \mathrm{R}$ & \multicolumn{1}{c}{10} & 0 & \multicolumn{1}{c}{-9} & -18 \\
\hline & & & & & & & \\
Time to Ignite (sec) & 4.0 & 5.5 & 5.0 & 3.5 & 5.0 & 40.0 & 360.0 \\
Time to Equil (min) & 59.0 & 62.0 & 19.0 & 61.0 & 80.0 & 59.0 & 103.0 \\
Temp Lamp A ( $\left.{ }^{\circ} \mathrm{C}\right)$ & 57.0 & 50.7 & 49.8 & 36.0 & 24.8 & 7.9 & -2.6 \\
Temp Lamp B & 58.3 & 48.3 & 49.3 & 36.3 & 31.6 & 17.2 & 5.2 \\
Temp Lamp C & 62.2 & 47.1 & 46.0 & 32.4 & 31.5 & 13.9 & 1.7 \\
Flicker Index & 0.05 & 0.06 & & 0.11 & 0.08 & 0.11 & \\
Lamp Lum (cd/m ${ }^{2}$ ) & 17.6 & 13.8 & 18.2 & 18.4 & 14.8 & 9.1 & 4.6 \\
Lamp Volts & 0.25 & 0.19 & 0.25 & 0.26 & 0.22 & 0.13 & 0.08 \\
LumEff (cd/m $/$ Watts) & 0.09 & 0.09 & 0.12 & 0.12 & 0.09 & 0.06 & 0.03 \\
Relative LumEff & 1.00 & 1.00 & 1.32 & 1.35 & 1.07 & 0.67 & 0.35 \\
Power (watts) & 58.3 & 45.7 & 45.59 & 45.23 & 45.8 & 44.66 & 43.2 \\
Power (Volt/amps) & 107.6 & 88.4 & 84.71 & 81.86 & 83.8 & 88.06 & 87.29 \\
Power Factor & 0.54 & 0.52 & 0.54 & 0.55 & 0.55 & 0.51 & 0.49 \\
THD Voltage & & 3.8 & 3.8 & 3.8 & 3.8 & 3.9 & \\
THD Current & & 10.3 & 11.2 & 10.8 & 9.7 & 9.7 & \\
Input Voltage & 122.0 & 122.0 & 121.7 & 122.0 & 121.7 & 121.8 & 121.8 \\
Input Current & 882.0 & 724.6 & 696.0 & 671.0 & 682.0 & 722.0 & 717.0 \\
Burn Time (min) & 77.0 & 102.0 & 54.0 & 102.0 & 118.0 & 69.0 & 103.0
\end{tabular}

Lamp 12 (lamp voltage boosted to $13 \mathrm{v}$ to get start)

\begin{tabular}{|c|c|c|c|c|c|c|}
\hline Ambient & 45 & $25 \mathrm{R}$ & 10 & 0 & -9 & -18 \\
\hline Time to Ignite (sec) & 5.0 & 5.0 & 5.0 & 5.0 & failed & \\
\hline Lamp Lum $\left(\mathrm{cd} / \mathrm{m}^{2}\right)$ & 10.6 & & 6.5 & 3.5 & & \\
\hline Lamp Volts & 0.26 & & & & & \\
\hline
\end{tabular}

Lamp 13

\begin{tabular}{lrrrrrrr}
${ }^{\circ} \mathrm{C}$ & \multicolumn{1}{c}{ Ambient } & \multicolumn{1}{c}{25} & $25 \mathrm{R}$ & 10 & 0 & \multicolumn{1}{c}{-9} & -18 \\
\hline Time to Ignite (sec) & 0.5 & 0.5 & 0.5 & 0.5 & 0.5 & 0.5 & 0.5 \\
Time to Equil (min) & 15.0 & 20.0 & 19.0 & 16.0 & 15.0 & 15.0 & 15.0 \\
Temp Lamp A ( ${ }^{\circ} \mathrm{C}$ ) & 66.4 & 56.9 & 52.7 & 38.2 & 27.6 & 17.8 & 10.7 \\
Temp Lamp B & 66.7 & 55.0 & 57.8 & 41.2 & 34.6 & 23.5 & 14.1 \\
Temp Lamp C & 67.7 & 58.1 & 53.4 & 38.0 & 33.0 & 17.4 & 14.7 \\
Flicker Index & NONE & & & & & & \\
Lamp Lum (cd/m ${ }^{2}$ ) & 12.7 & 13.6 & 13.6 & 12.6 & 12.6 & 13.7 & 13.5 \\
Lamp Output (volts) & 0.18 & 0.19 & 0.19 & 0.19 & 0.19 & 0.20 & 0.20 \\
LumEff (cd/m /Watts) & 0.02 & 0.02 & 0.02 & 0.02 & 0.02 & 0.02 & 0.02 \\
Relative LumEff & 0.94 & 1.00 & 1.01 & 0.93 & 0.93 & 1.02 & 1.00 \\
Power (Watts) & 164.7 & 166.3 & 164.8 & 164.9 & 165.0 & 164.6 & 165.1 \\
Power (Volt/amps) & 165.1 & 166.4 & 164.9 & 165.0 & 163.1 & 164.7 & 165.0 \\
Power Factor & 1.0 & 1.0 & 1.0 & 1.0 & 1.0 & 1.0 & 1.0 \\
THD Voltage & 3.9 & & 3.9 & 3.9 & 3.9 & 3.9 & 3.9 \\
THD Current & 3.9 & & 3.9 & 4.0 & 3.9 & 4.0 & 4.0 \\
Input Voltage & 121.6 & 122.9 & 121.9 & 121.9 & 121.8 & 121.8 & 122.0 \\
Input Current & 1353.0 & 1374.0 & 1353.0 & 1354.0 & 1354.0 & 1353.0 & 1354.0 \\
Burn Time (min) & 135.0 & 62.0 & 34.0 & 111.0 & 56.0 & 98.0 & 47.0
\end{tabular}


voltage, input current, and burn time for each test. Blanks in the table represent conditions for which no data were obtained with the BMI.

Because of the difficulty of comparing performance for different lamps from table 2, many of these data are summarized graphically. In the following figures the upper plot refers to lamps 1 through 6 , while the lower plot presents data for lamps 7 through 13. Figure 13 which presents time to ignition as a function of ambient temperature for temperatures greater than $-18^{\circ} \mathrm{C}$ makes it very clear that time to ignition was greatly affected by temperatures below $0^{\circ} \mathrm{C}$, particularly lamps $5,6,7$, 10 and 11 (as well as 8 which failed completely at these temperatures.)

For these lamps, ignition time increased from less than 5 seconds to 40 or more seconds. At $-18^{\circ} \mathrm{C}$, the time to ignition increased to 400 to 500 seconds for lamps $5,6,7,10$, and 11. At the same time, ignition time for the incandescent lamp, 13, remained at less than 0.5 seconds, regardless of changes in ambient temperature. Figure 14 summarizes the data presented above on time to equilibrium as a function of ambient temperature. While there may be a trend toward increasing time with decreasing temperature, these two plots demonstrate a great deal of variability in the general trends. Table 2 indicates the time to equilibrium for lamps $2,4,8$, and 10 between the first test at $25^{\circ} \mathrm{C}$ and the second, suggests that they may not have been fully burned in at the beginning of the experiment. Figure 15 plots the lamp tip temperature (for the warmest of the three lamps) as a function of ambient temperature. These two graphs make it very clear that lamp tip temperature declined markedly as ambient temperature decreased which probably explains the drop in performance that occurred with lower temperatures. By $10^{\circ} \mathrm{C}$ lamp tip temperature for lamps 1,6 , and 7 was below $30^{\circ} \mathrm{C}$ which is below the temperature for which optimum performance is expected for fluorescent lamps (IESNA, 1984). By $-9^{\circ} \mathrm{C}$, all lamps had lamp tip temperatures below this temperature. Lamp tip temperature was something of a misnomer for lamps 2, 4, and 6 which were comprised of a globe around the lamp itself. Comparison of the temperatures for lamps 5 and 6 in figure 15 demonstrate the likely thermal effects of the globe with lamp 5 having the warmest and lamp 6 having the coolest temperatures plotted in Figure 15a.

Figures 16 and 17 present data on lamp light output for the different ambient temperatures, with Figure 16 being measured luminance data and figure 17 being photocell output (as discussed in figures 1 through 12). Not unexpectedly, the output figures are virtually identical (even though the measurements were obtained with different procedures and instruments). Each plot generally shows declining output with decreasing temperature. Lamps 1, 3, 6, 7, and 9 demonstrated a sharp decrease in luminance and photocell output with temperature, with lamps 1 and 7 showing a decrease by $10^{\circ} \mathrm{C}$. The decline in output was much less pronounced for lamps 2,4 and, of course, 13. The repeated measures at $25^{\circ} \mathrm{C}$ demonstrated relatively little change from the initial measures.

While the primary means for monitoring the light output of the lamps was a silicon photocell located within the environmental chamber, a supplemental procedure was developed to account for any thermal instabilities of the photocell. In this procedure, the luminance of a white tile located below the lamps was measured to evaluate whether the photocell response changed with ambient temperature. For these measures, a luminance meter which was kept outside the environmental chamber, was brought into the chamber very briefly and used to measure the luminance of the white tile. Because the luminance of the tile is proportional to lamp light output, and independent of ambient temperature, it can be used to verify the thermal stability 
Figure 13. Ignition Time for all Lamps at Ambient Temperatures Above $-18^{\circ} \mathrm{C}$.

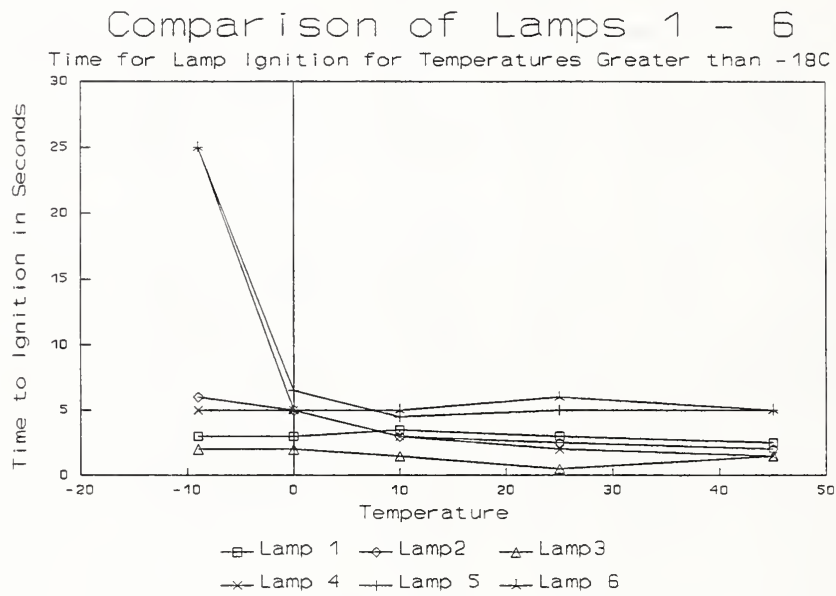

Compar ison of Lamps 7 to 13 Time to Ignition for Temperatures Greater Than -18C

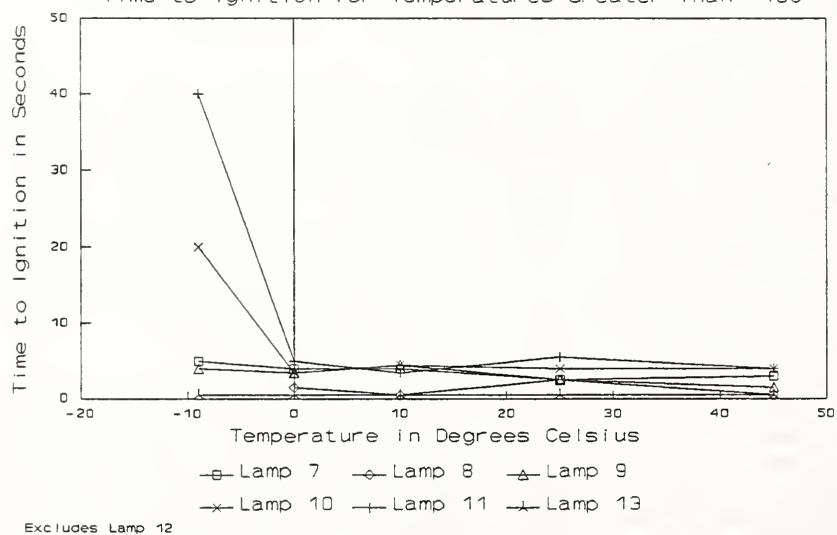


Figure 14. Time to Luminous Equilibrium at Different Ambient Temperatures.
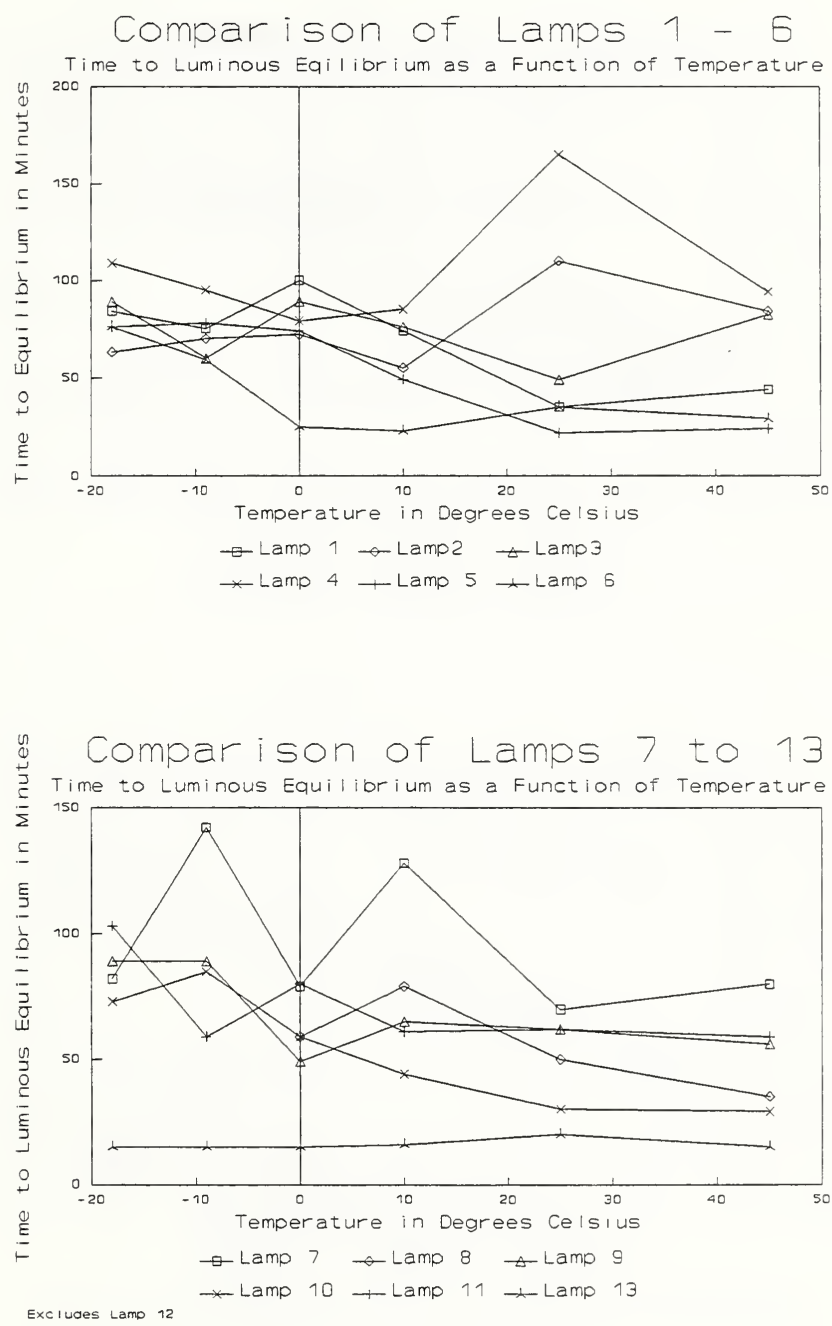
Figure 15. Lamp Outer Wall Temperature at Different Ambient Temperatures.
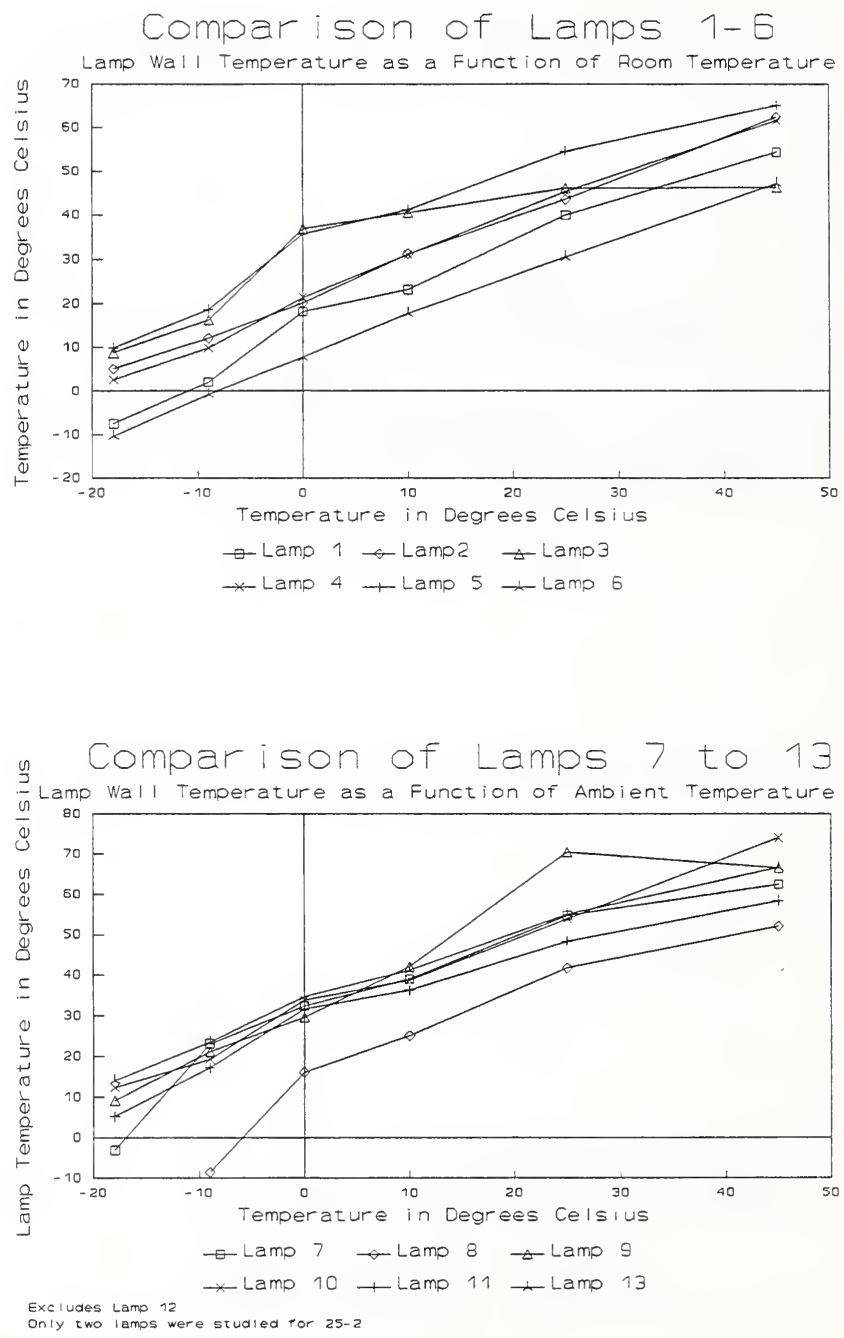
Figure 16. Measured Luminance at Different Ambient Temperatures.

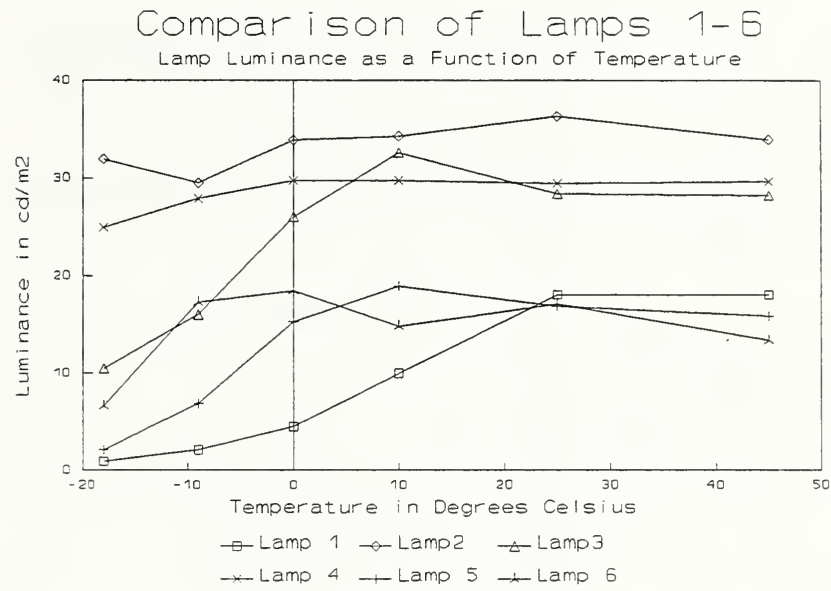

Comparison of Lamps 7 to 13 Lamp Luminance as a Function of Temperature

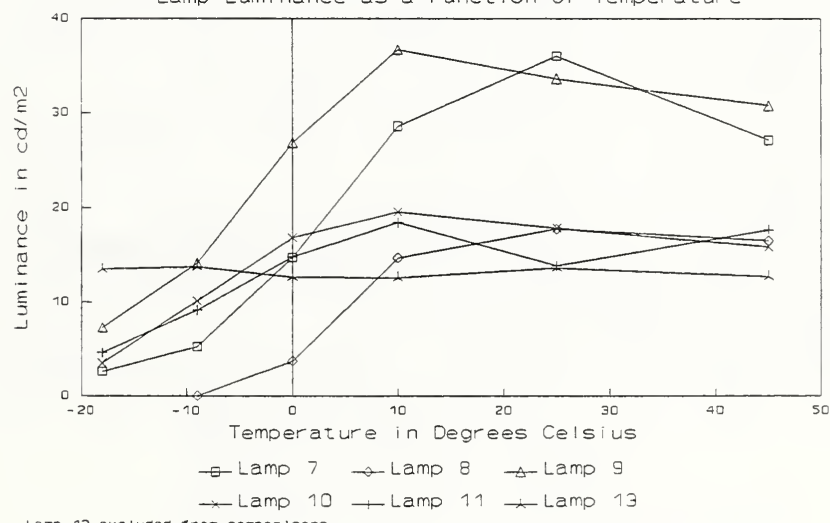

Lamp 12 excluded from comparisons 
Figure 17. Measured Light Output at Different Ambient Temperatures.

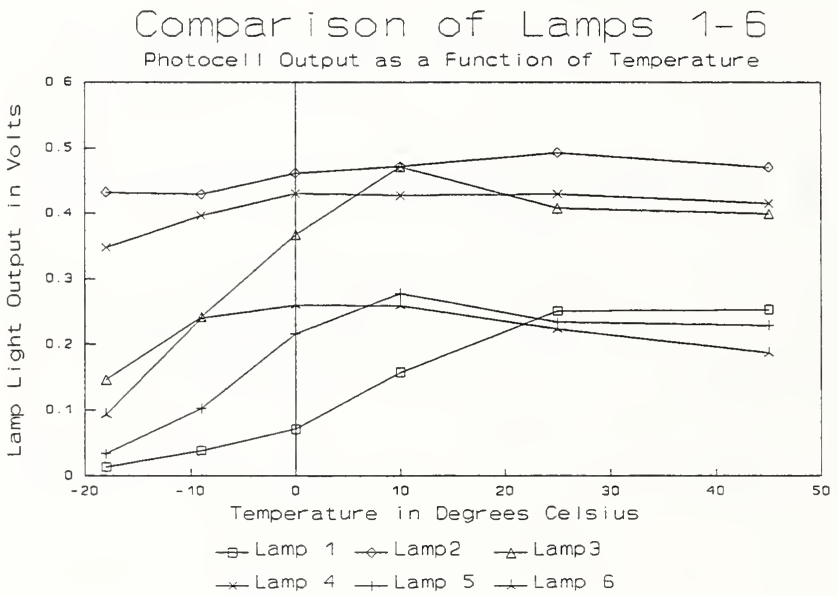

Comparison of Lamps 7 to 13 Photocell Output as a Function of Temperature

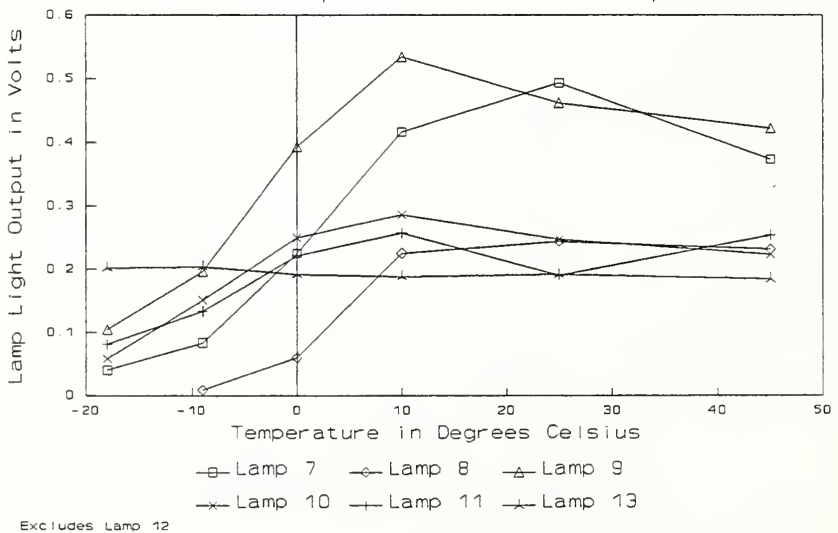


of the photocell. It provided further data on the light output of the lamps for a standard condition, although it did not, of course, provide absolute luminance data.

Comparison of the photocell and luminance meter measures indicated insignificant temperature dependence for the photocell under the range of testing conditions, with differences for individual lamps ranging from 0.009 to 0.18 . The average difference between meter readings for all lamps for all temperatures was 0.014 with a standard deviation of 0.001 . Figure 18 presents a graphical rendition of the photocell light output relative to that for the luminance meter as a function of temperature for lamps 1 to 6 and 7 to 13. Inspection of these graphs reveals good agreement between the two types of measures with the best agreement occurring at 10 and $25^{\circ} \mathrm{C}$. This analysis thus indicates that the photocell remained sufficiently stable over temperature that comparisons between the performance of different lamps at different temperatures can be made.

Figure 19 plots input power in watts as a function of temperature for the different lamps. As can be seen, input wattage generally remained relatively constant with marked decreases only for lamps 5 and 6 at $-18^{\circ} \mathrm{C}$ and for 7 and 8 at $-9^{\circ}$ and $-18^{\circ} \mathrm{C}$ (because one or more lamps had failed at these temperatures). These plots make it very clear that the incandescent lamp, 13, required the greatest power although lamps 7,8 and 9 (being 24 watts or more) required more power than the other lamps. Figure 20 which plots relative luminous efficacy is a comparison of lamp luminous output divided by input power relative to the same lamp's performance at $25^{\circ} \mathrm{C}$. While total lamp lumen output was not measured directly, the photocell reading provided a measure of relative luminous output.

Consequently, lamp efficacies could be compared for each set of lamps at different thermal conditions. This comparison was termed relative luminous efficacy. Comparison between lamps is only an approximation because the lamps differed in size and distance from the photocell. As a result the photocell could not measure the total luminous distribution. Nonetheless, examination of the two plots in figure 20 makes it very clear that the relative luminous efficacy for the incandescent lamp, 13, remained relatively constant as temperature varied. All the compact fluorescent lamps, however, showed reduced output at the colder temperatures, with markedly reduced output at $-18^{\circ} \mathrm{C}$. Only lamps 2 and 4 appeared to be somewhat unaffected by temperature with relative luminous efficacies greater than 0.8 throughout the experiment. Lamps 1 and 8 , on the other hand showed markedly reduced efficacy even at $10^{\circ} \mathrm{C}$ with a pronounced decline for lower temperatures. Comparison of lamps 5 and 6 reveals that when the globe was used, relative luminous efficacy increased, but when it was not used efficacy dropped dramatically for 0 and $-9^{\circ} \mathrm{C}$. This is 1 ikely due to heating of the lamp when enclosed by the globe. Efficacy declined markedly for both configurations at $-18^{\circ} \mathrm{C}$, however. Inspection of the lower plot reveals that lamps 9,10 , and 11 actually increased their efficacy at $10^{\circ} \mathrm{C}$, while 7 and 8 began to decline. (Relative efficacy for these two lamps was, of course, markedly affected by the failure of one or more lamps below $10^{\circ} \mathrm{C}$.) 
Figure 18. Photocell Output Relative to Luminance Meter Output as a Function of Ambient Temperature.
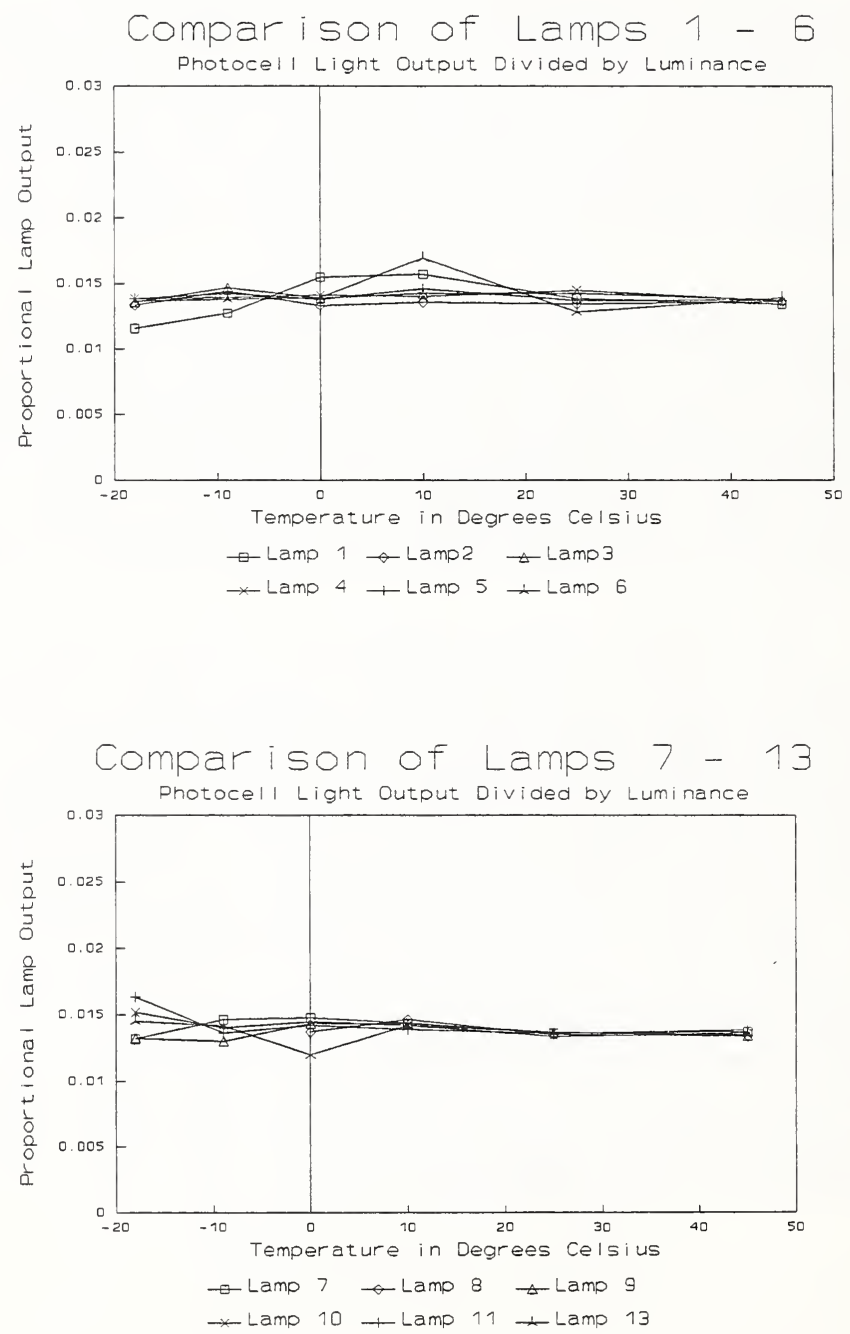
Figure 19. Lamp and Ballast Power in Watts at Different Ambient Temperatures.
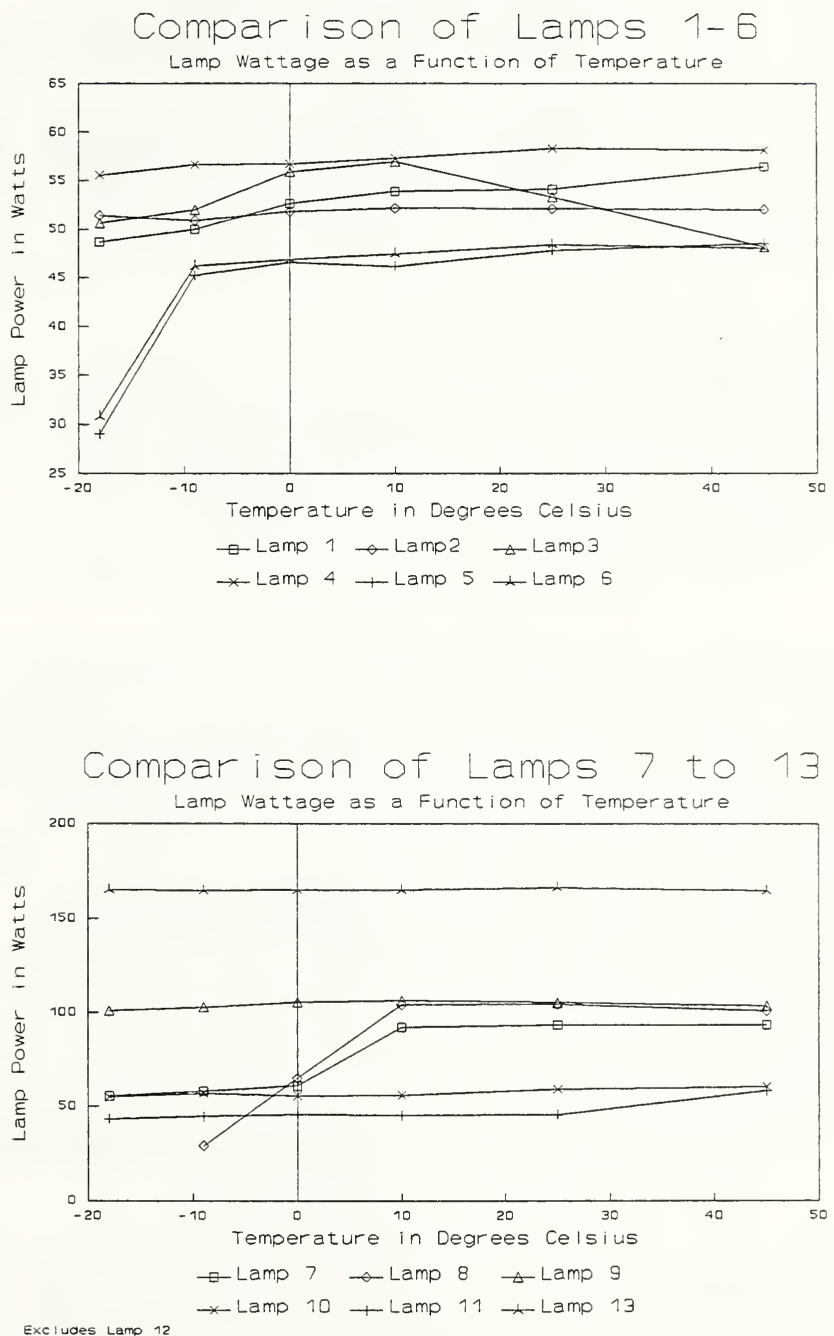
Figure 20. Luminous Efficacy Relative to that at $25^{\circ} \mathrm{C}$ for Different Ambient Temperatures.

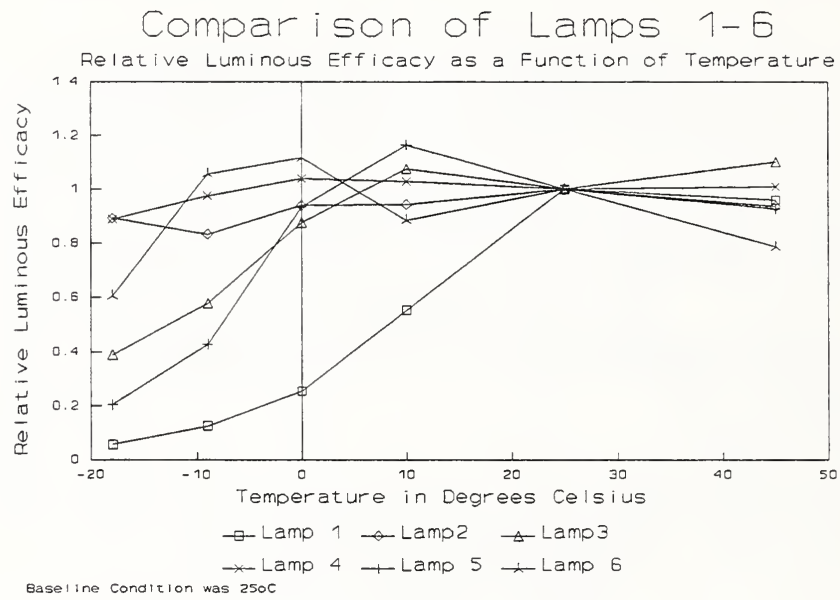

Comparison of Lamps 7 to 13

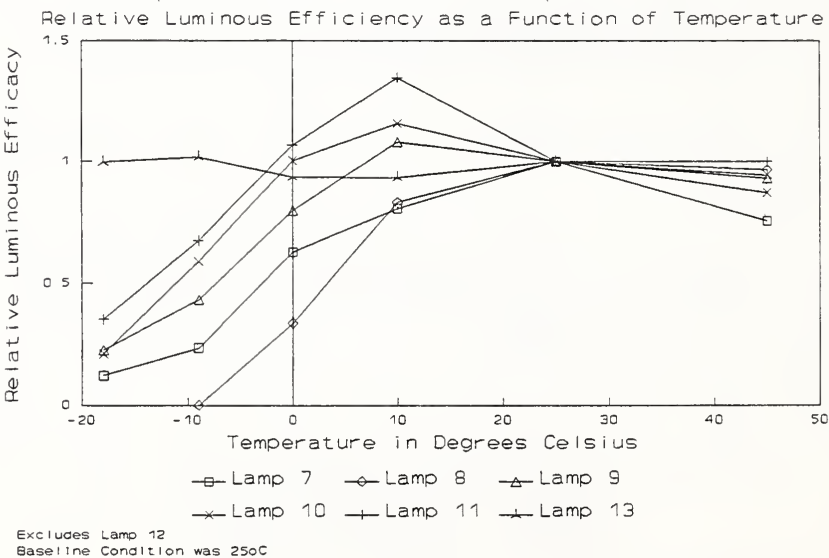


Despite the decreases in relative luminous efficacy, for most of the temperature tests, relative luminous efficacy remained greater for the compact fluorescent lamps compared with that of the incandescent. Perhaps the most interesting comparison data are given in Figure 21 which plots relative lamp efficacy relative to that for lamp 13 at $25^{\circ} \mathrm{C}$ and provides an indication of compact fluorescent performance against the reference incandescent lamp. This comparison is instructive, indicating that for temperatures above $-9^{\circ} \mathrm{C}$, relative luminous efficacy was much greater for the compact fluorescents, despite their declining output at colder temperatures. By $0^{\circ} \mathrm{C}$, only two lamps, 1 and 8 had efficacies below that of the incandescent lamp. By $-18^{\circ} \mathrm{C}$, the efficacy for lamps $1,5,8$ (which had totally failed), 7 (which was lacking one lamp but which had been well above lamp 13 even for $0^{\circ} \mathrm{C}$ ), 9 and 10 had fallen below that of lamp 13. At least two lamps, 2 and 4, maintained reasonably high relative luminous efficacies throughout all the test temperatures. Even at $-18^{\circ} \mathrm{C}$ their relative efficacy was 6 to 8 times that of the incandescent lamp.

Figure 22 compares lamp apparent power in volt amps as a function of temperature. Inspection of the two plots in this figure suggests that input volt amps tended to remain relatively stable over temperature for most lamps. Some lamps such as $2,4,10,11$, and 13 displayed almost no variation in volt amps across temperatures. The ones with the greatest variation were $1,3,5,6,7$ and 8 . The latter two varied of course, because of the loss of one or more lamps at cold temperatures. Figure 23 which graphs input current for the different ambient temperatures demonstrates that it tended to decrease for lamps 1 and 4 , but remain relatively constant for the other lamps (except 5, 6, and 8 which experienced ignition problems at temperatures below $-9^{\circ} \mathrm{C}$ ).

Figure 24 demonstrates that power factor generally was around 0.55 with some variations due to temperature (primarily for lamp 1). This figure makes it clear that power factor did not vary much for different temperatures (except lamp 8 which was close to failure at $-9^{\circ} \mathrm{C}$ ). It also demonstrates that power factor was generally about 0.55 for all lamps except 3,8 , and of course 13 which was at 1 as expected. Only lamp 8 of the compact fluorescents had a power factor near 1, which dropped dramatically for $-9^{\circ} \mathrm{C}$ to about 0.25 . (This lamp contained a high power factor correction circuit as well as a constant illumination circuit.) Figure 25 presents the calculated flicker index, which demonstrates that flicker generally increased as temperature decreased. Because of the number of transformations to these data, only the general trends are relevant; the variability may reflect the uncertainty of the digitizing technique. Figures 26 and 27 which present data for harmonic distortion, for both current and voltage, demonstrate little variation in these parameters as a function of temperature for the performance of the different lamps. Lamps 3, 4, and 7 had higher total harmonic distortions for both current and voltage than the other compact fluorescent lamps, however, regardless of temperature. (The variation observed for lamp 7 was due solely to the breakage of one lamp and should not be considered further. Inspection of its performance for 2 lamps at $25^{\circ}$ (labeled as 25-2) indicates no change as a function of repeated exposure to different temperatures.)

Finally, Figure 28 compares performance for the different lamps at $25^{\circ} \mathrm{C}$ taken at the beginning and end of the testing sessions. Inspection of the data on time to equilibrium, light output, and relative lamp efficacy suggests that the lamps were not harmed by the thermal extremes (as we had hypothesized that they might be.) Rather the data suggest that the 100 hours of burn time prior to the thermal testing may not have been quite long enough to age and stabilize the lamps completely - or that the procedures for data collection may have increased in stability during the course of the experiment. 
Figure 21. Luminous Efficacy Relative to that of Lamp 13 (Incandescent) at Different Ambient Temperatures.
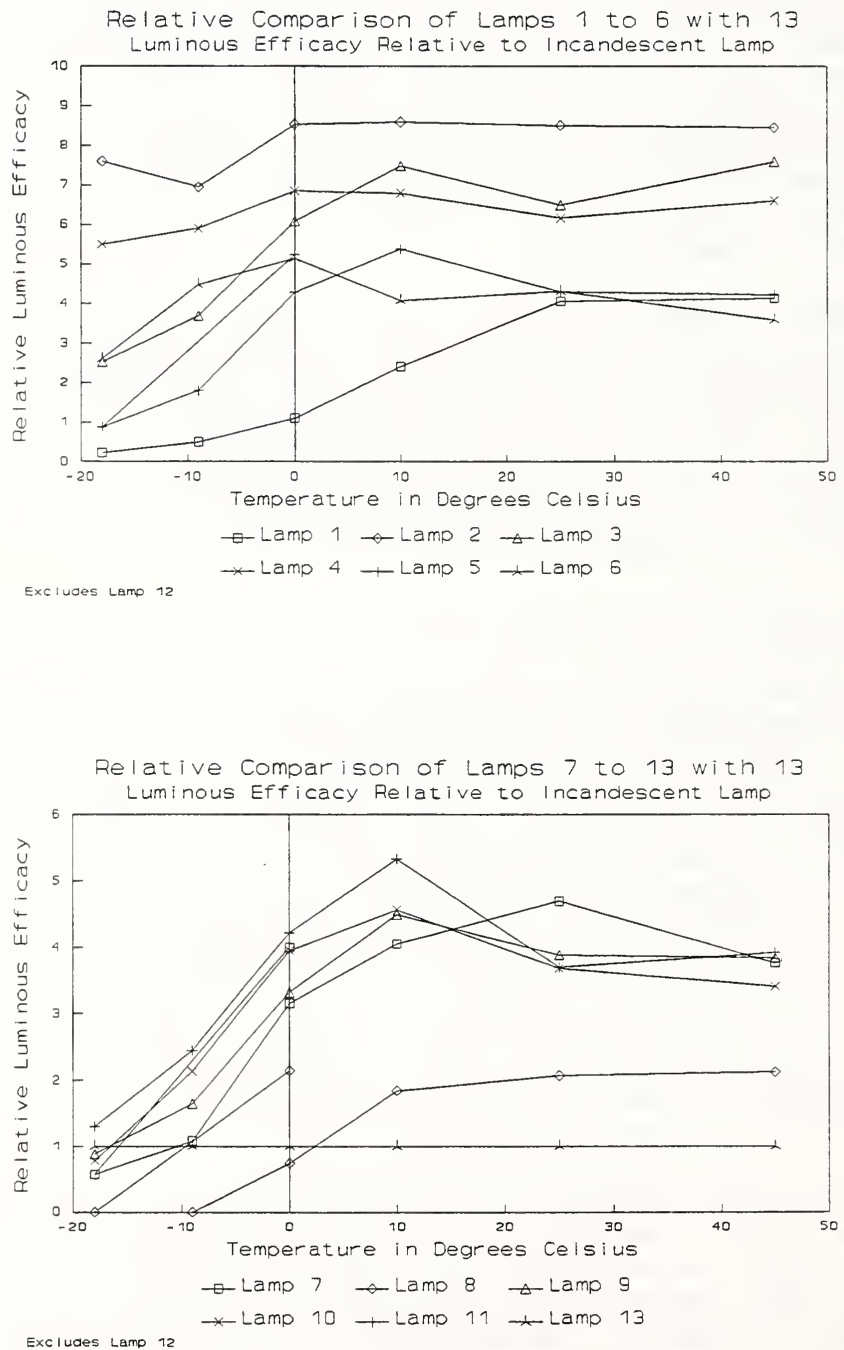
Figure 22. Apparent Power (in Volt Amps) at Different Ambient Temperatures.
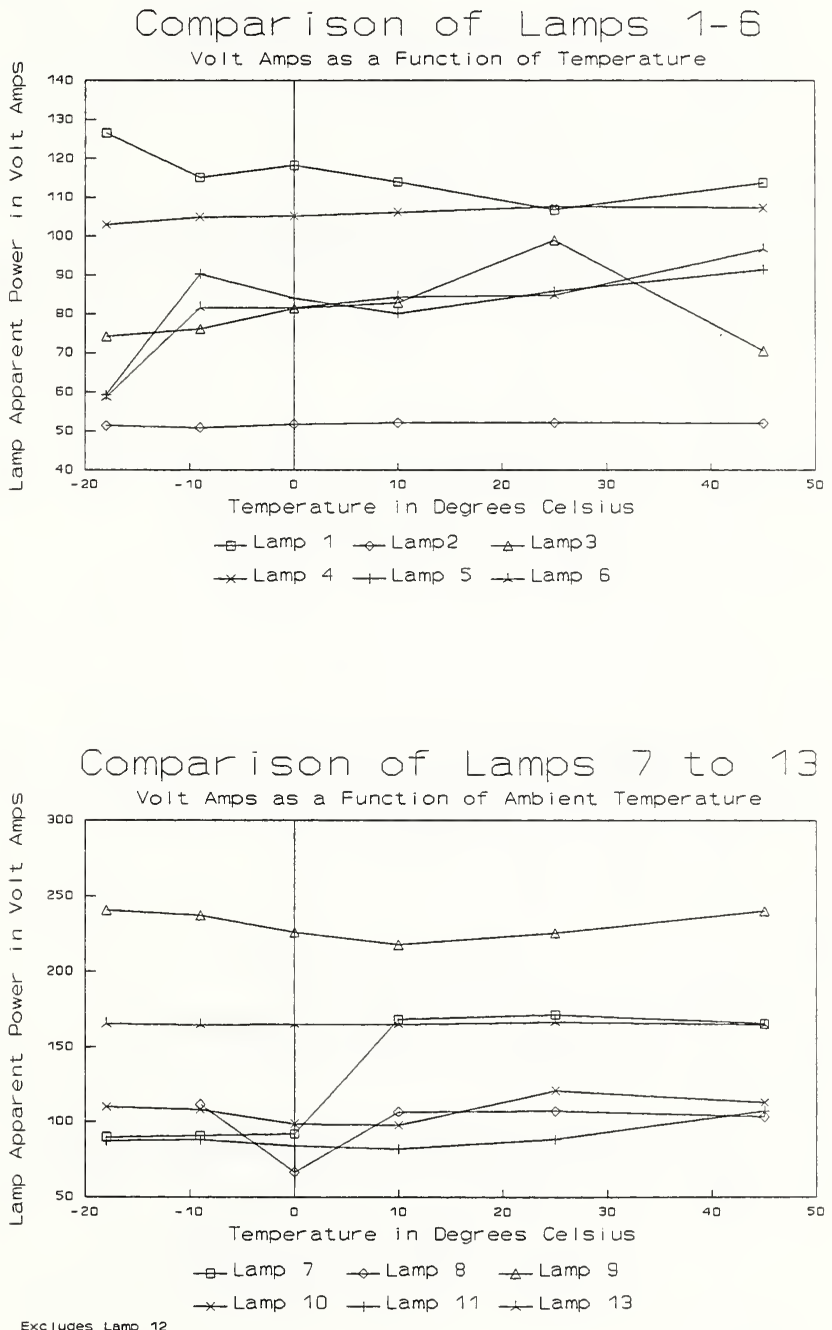
Figure 23. Supply Current at Different Ambient Temperatures.

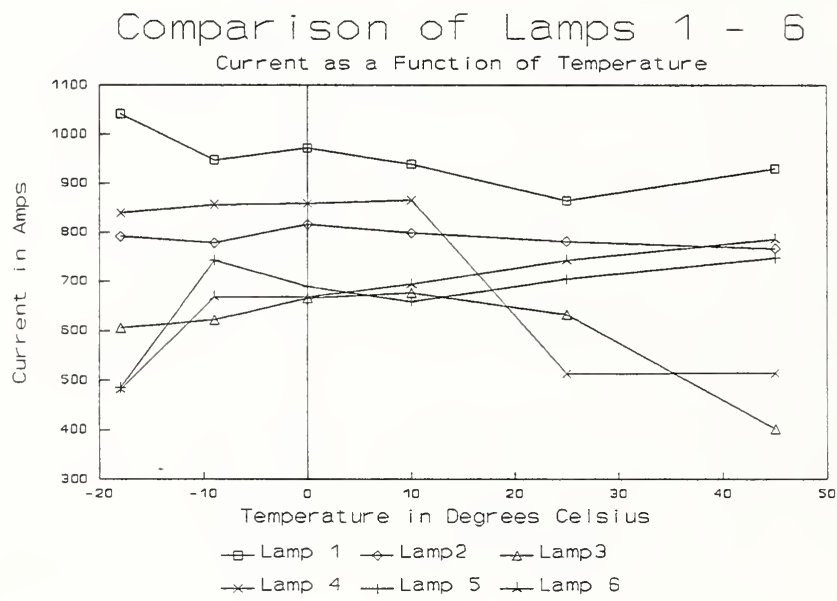

Comparison of Lamps 7 to 13

current as a Function of Temperature

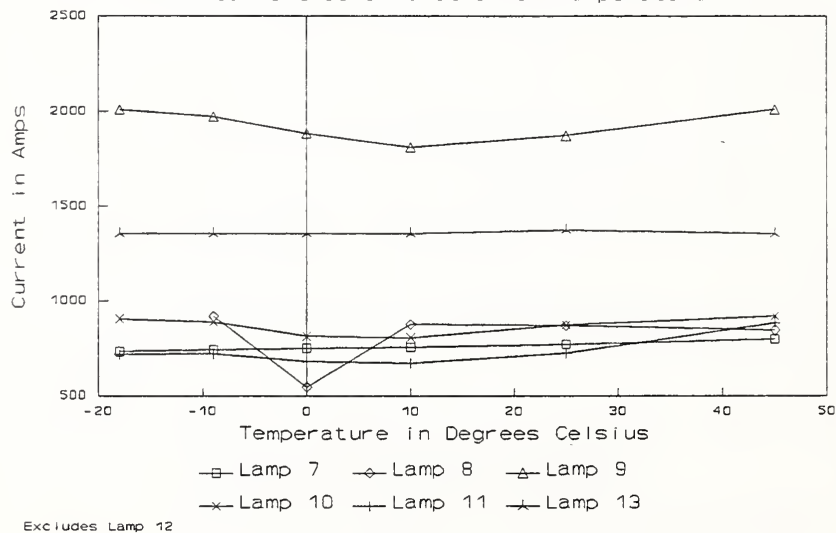


Figure 24. Power Factor at Different Ambient Temperatures.
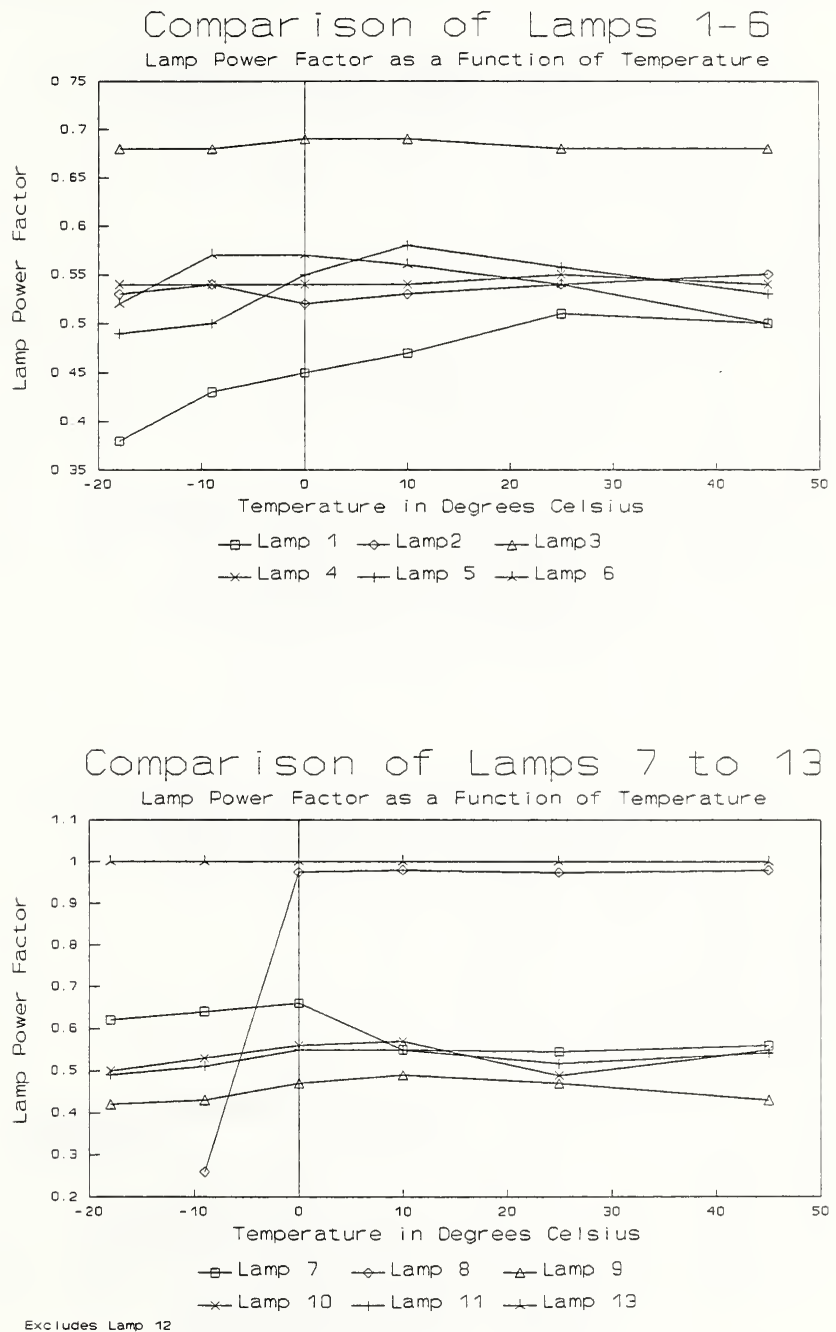
Figure 25. Calculated Flicker Index at Different Ambient Temperatures.
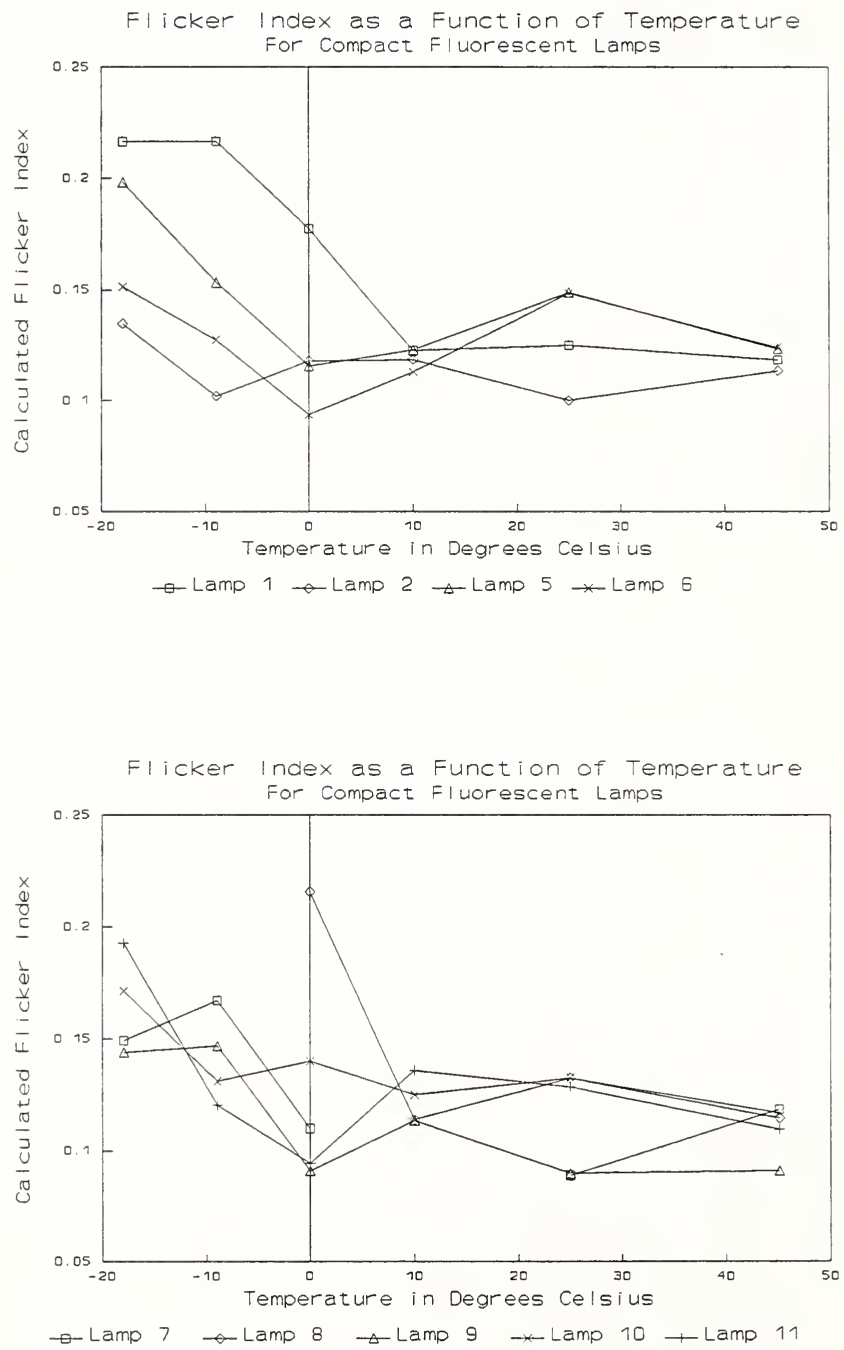
Figure 26. Total Harmonic Distortion for Current at Different Ambient Temperatures.
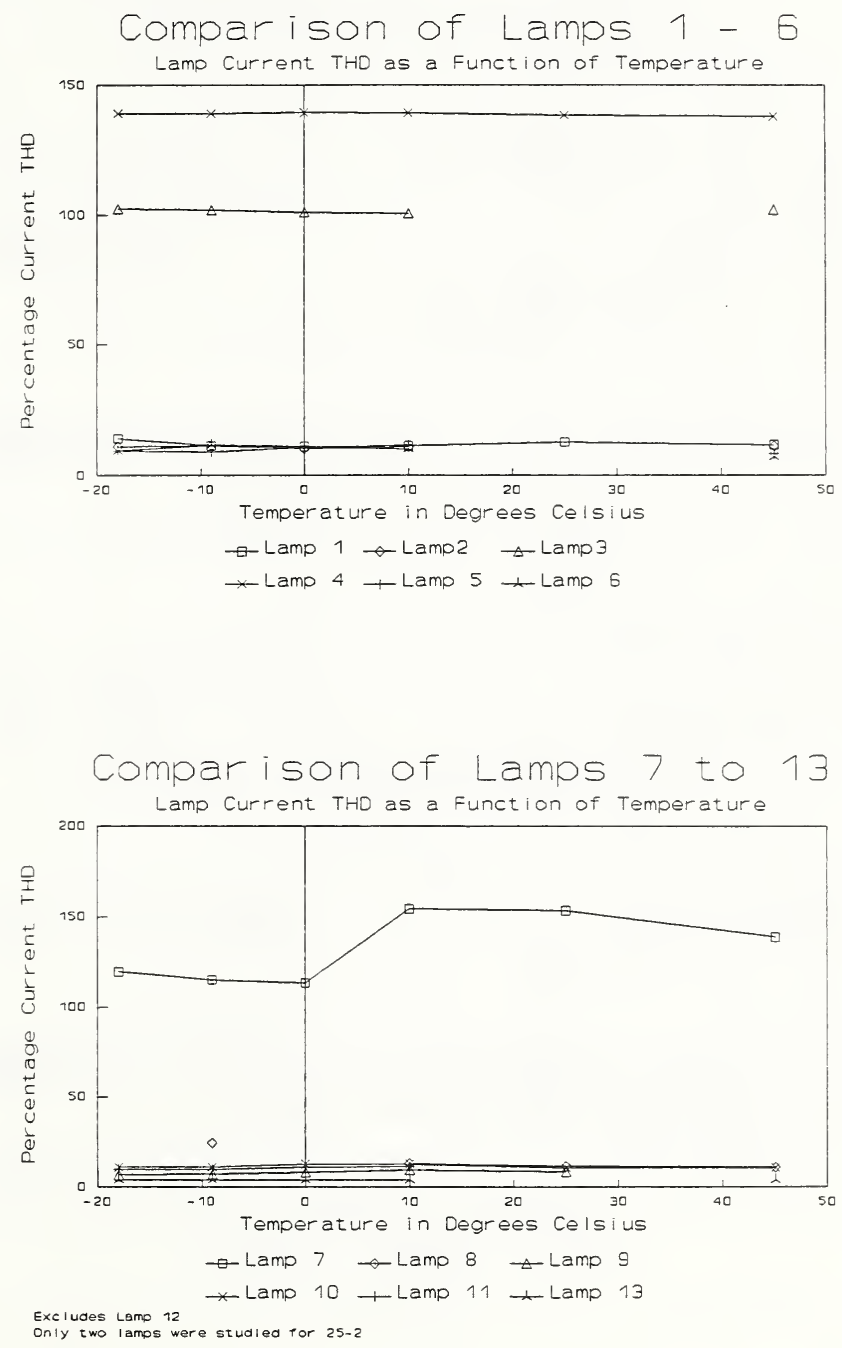
Figure 27. Total Harmonic Distortion for Voltage at Different Ambient Temperatures.
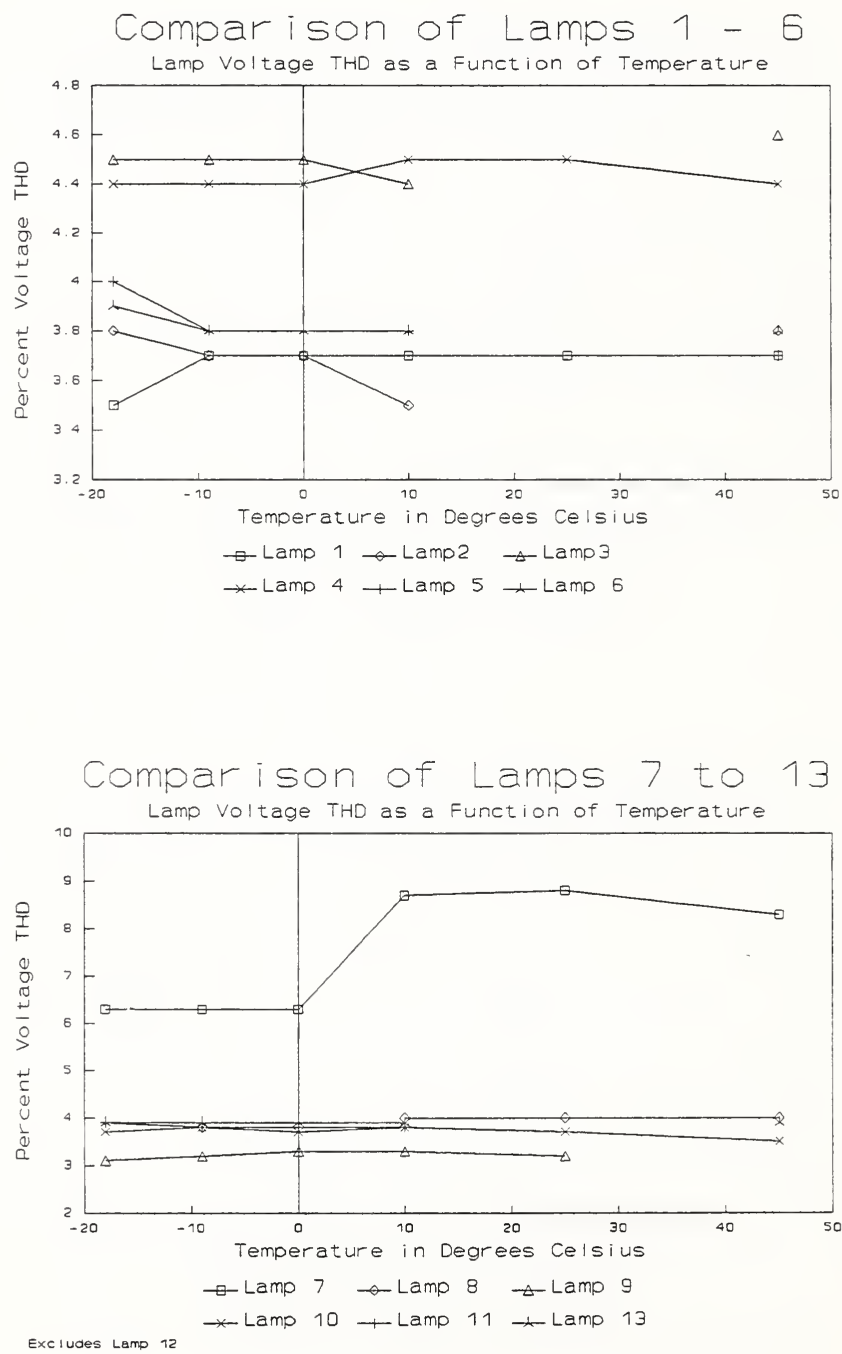
Figure 28. Comparison of Initial and Repeated Performance at $25^{\circ} \mathrm{C}$.
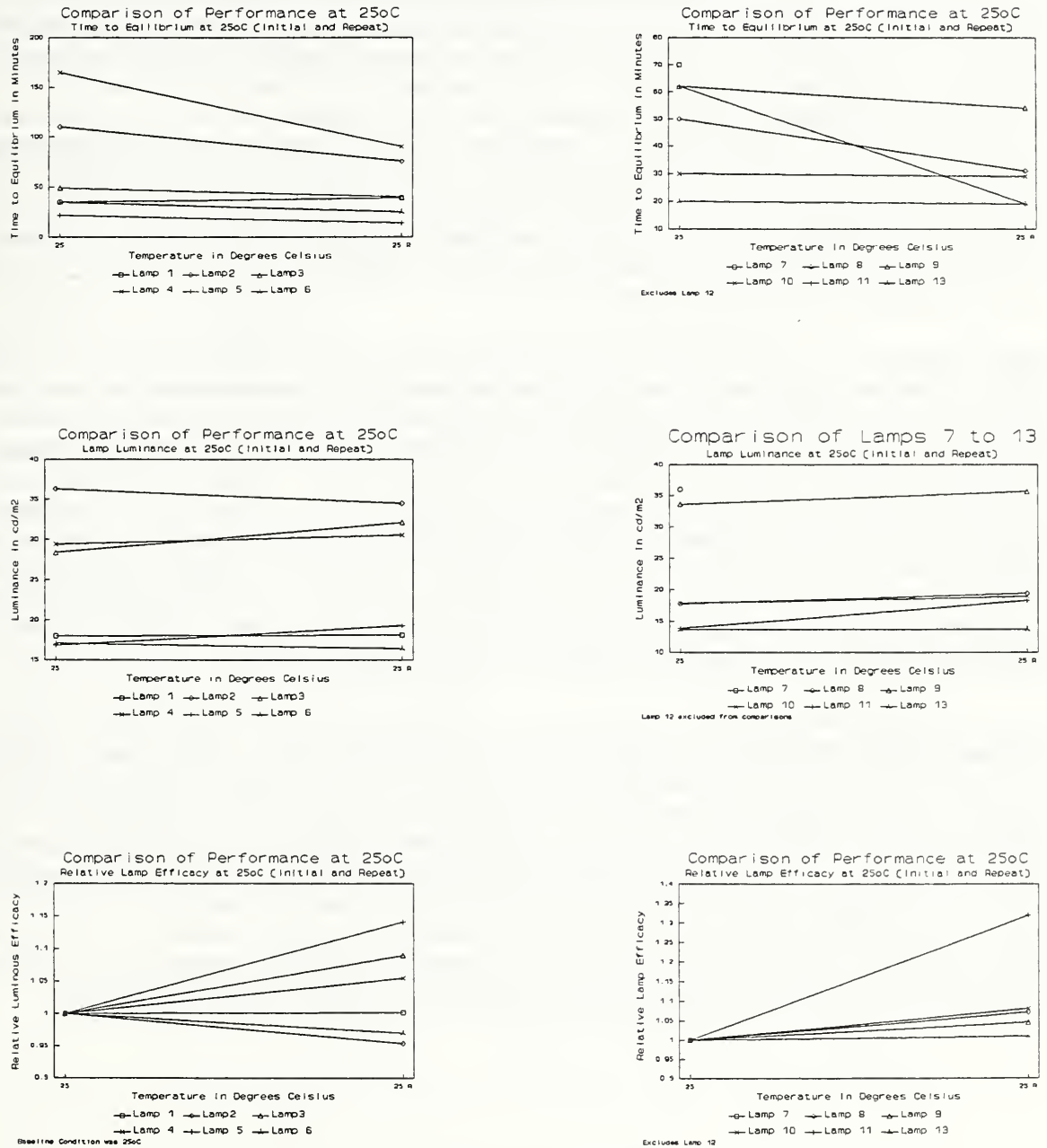
The most important conclusion to be reached from these data is that temperature variations from the "normal" temperature of $25^{\circ} \mathrm{C}$ greatly reduced lamp light output and increased the time to luminous equilibrium. Lamps that were markedly affected by temperature displayed noticeable reductions in light output - sometimes being reduced to $10-20 \%$ or less of their output at the baseline $25^{\circ} \mathrm{C}$ temperature - and outright failure in other cases. In addition, their time to equilibrium demonstrated much greater variability. This finding is in accordance with results generally found for conventional fluorescent lamp performance (Siminovitch, Rubenstein, and Verderber, 1984; Treado and Bean, 1990, 1991). The only design factor which appeared to moderate this finding was the presence of an outer globe surrounding the fluorescent tube. Lamps using this configuration did not suffer the declines in light output at low temperatures experienced by the other compact fluorescents. Their light output declined for higher temperatures, however.

Despite reductions in performance due to temperature extremes, the other major conclusion is that the compact fluorescent lamps remained noticeably more efficient than the comparison incandescent lamp until very low temperatures (usually below freezing, $0^{\circ} \mathrm{C}$ ) were reached. These lamps consistently produced more light output for less power input, as compared with the reference incandescent lamp. This effect varied for lamp type - those with an enclosing globe tended to demonstrate less performance decrement at the lower temperatures. The low voltage system was not particularly successful, however, perhaps because of the novelty of the design which resulted in inadequate isolation of the electrical components in the test situation. As others have reported, power factor for the compact fluorescents was typically low, around 0.55 , for the compact fluorescent designs studied, while harmonic distortion was noticeably higher for three of the lamps studied. Flicker index was in line with reported data for other types of fluorescent lamps (IESNA, 1984).

The data suggest, however, that the selection of a particular compact fluorescent system should be based on its likely application. If the space is likely to be cold, then a lamp with an integral enclosure (or globe) should be selected for maximum light output. If it is likely to be hot (above $25^{\circ} \mathrm{C}$ ) then such an enclosure is likely to overheat the lamp, resulting in lower light output suggesting that a lamp without an enclosure would be more appropriate. Still another factor for design consideration is the marked variation in size of the different lamps and ballasts. In addition, for some of the lamps the ballast was an integral component of the fixtures, whereas for others, such as lamps 7,8 , and 9 , the ballast was separate and required wiring before use. Finally, the compact fluorescents studied here tended to decrease in light output over the time of operation at extreme temperatures, particularly when stressed by temperature, another factor which may be of concern in some applications. 


\section{References}

Arseneau, R. and Ouellette, M.J. Effects of Harmonics on the Performance of Compact Fluorescent Lamps, accepted for Proceedings of the International Conference on Harmonics in Power Systems, Atlanta GA, Sept 23-25, 1992.

Bouwknegt, A. Compact Fluorescent Lamps. Journal of the Illuminating Engineering Society, 1982, 11, Pp. 204-212.

Finn, D., and Ouellette, M.J. Compact Fluorescent Lamps: What You Should Know, Progressive Architecture, August, 1992, pp. 89-92. IRC Paper No. 1840, NRCC\# 34057, 1992.

Kaufman, J.E. and Christensen, J.F. (Eds.). IES Lighting Handbook; Reference Volume. New York: IESNA, 1984, Chapter 8.

Ouellette, M.J. and Arseneau, R. Effects of Undervoltage on the Performance of Compact Fluorescent Systems, accepted for publication in Proceedings of Annual Conference of IEEE Industry Applications Society., Houston TX, Oct 4-9. IRC Paper No. 1823, 1992.

Ouellette, M.J. Photometric Errors with Compact Fluorescent Sources, accepted for publication in Proceeding of Annual Conference of IEEE Industry Application Society., Houston TX, Oct 4-9. IRC Paper No. 1766, 1992.

Siminovitch, M.J., Rubenstein, F.M., and Verderber, R.R. Determining Lamp/Ballast System Performance with a Temperature-Controlled Integrating Chamber. Journal of the Illuminating Engineering Society, 1984, 14, Pp. 364-378.

Treado, S.J. and Bean, J.W. Measurement and Evaluation of Lighting and HVAC Interactions. National Institute of Standards and Technology, NISTIR 4429, 1990.

Treado, S.J. and Bean, J.W. The Interaction of Lighting, Heating and Cooling Systems in Buildings. National Institute of Standards and Technology, NISTIR 4701, 1991. 



\begin{tabular}{|c|c|}
\hline \multicolumn{2}{|l|}{ NIST-114 } \\
\hline $\begin{array}{l}\text { (REV. 9-92) } \\
\text { ADMAN 4.09 }\end{array}$ & NATIONAL INSTITUTE OF STANDARDS AND TECHNOLOGY \\
\hline & CRIPT REVIEW AND APPROVAL \\
\hline
\end{tabular}

INSTRUCTIONS: ATTACH ORIGINAL OF THIS FORM TO ONE (1) COPY OF MANUSCRIPT AND SEND TO: THE SECRETAAY, APPROPRIATE EDITORLAL REVIEW BOARD. TITLE AND SUBTITLE (CITE IN FULL)

Evaluation of Compact Fluorescent Lamp Performance at Different Ambient Temperatures

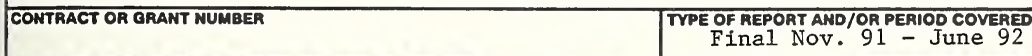

AUTHOR(S) (LAST MAME, FIRST INITIAL, SECOND INITIAL)

Collins, B.L., Treado, S.J., Ouellette, M.J.

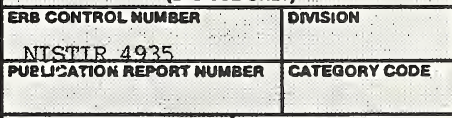

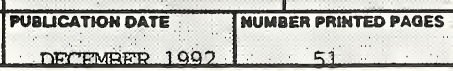

LABORATORY AND DIVSION MAMES (FIRST NIST AUTHOR ONLY)

Building \& Fire Research Laboratory/ Building Environment Division

SPONSORING ORGANIZATION HAME AND COMPLETE ADDRESS (STREET, CITY, STATE, ZIP)

National Research Council Canada

Montreal Road

Ottawa Ontario K1A OR6 CANADA

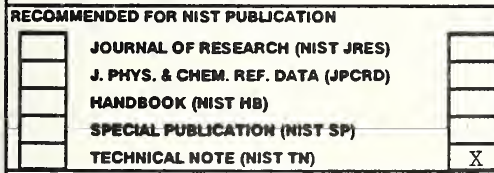

RECOMMENDED FOR NON-NIST PUBLCATION (CITE FULLV)

\section{MONOQRAPH (NIST MN)}

MATL STD. REF. DATA SERIES (MIST NSRDS)

FEDERAL INF. PROCESS. STOS. (MIST FIPS)

UST OF PUBUCATIONS (MIST LP)

NIST INTERAGENCY/INTERNAL REPORT (NISTIR)

PERFORMING ORGANIZATION (CHECK $(X)$ ONE BOX)

NIST/CATTHEASBURG

NIST/BOULDER

JLA/BOULDER

\begin{tabular}{l|l|l|l}
\hline & U.S. \\
\end{tabular}

PUBLISHING MEDIUM

SUPPLEMENTARY NOTES

ABSTRACT (A 1500-CHARACTER OR LESS FACTUAL SUMMARY OF MOST SIGNIFICANT INFORMATION. IF DOCUMENT INCLUDES A SIGNIFCANT BIBUOGRAPHY

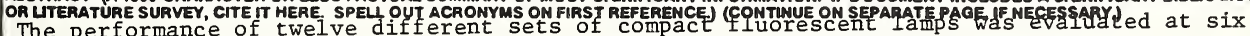

different temperatures ranging from $45^{\circ} \mathrm{C}$ to $-18^{\circ} \mathrm{C}$ and compared against the performance of

a set of comparable incandescent lamps. Performance measures included the following: lamp

ignition time or failure, time to luminous equilbrium and electrical stabilization, relative

luminous flux density, luminous flicker index for lamps with flicker rate below $240 \mathrm{~Hz}$, electrical power in watts (W) and volt amps (VA), minimum lamp wall or globe temperatue as applicable, relative luminous efficacy, total harmonic distortion, and power factor. In addition time to ignition was assessed for a simulated frost condition in which lamps were misted at $-4^{\circ} \mathrm{C}$. Analysis of the results indicated significant decremnts in performance for most compact fluorescent lamps at temperatures below $0^{\circ} \mathrm{C}$, with outright failure for several lamps at $-18^{\circ} \mathrm{C}$. Luminous output relative to the incandescent lamps renlained higher for comparable wattage lamps, however, except at the very coldest temperatures.

KEY WORDS (MAXIMUM 9 KEY WORDS; 28 CHARACTERS AND SPACES EACH; ALPHABETICAL ORDER; CAPITALUE ONLY PROPER MAMES)

Building technology, compact fluorescent, electrical, flicker, harmonic distortion, incandescent, lamp, luminous efficacy, power, power factor, temperature, voltage

\section{AVALABIUTY}

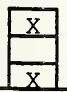

NOTE TO AUTMOR(S) IF YOU DO NOT WISH THIS MANUSCRIPT ANNOUNCED EEFORE PUBLICATION, PLEASE CHECK MERE. 

